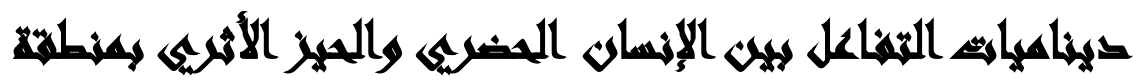

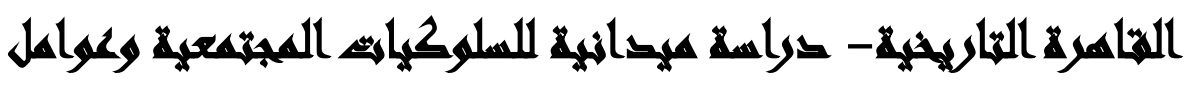

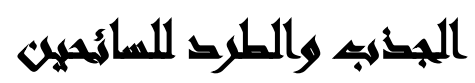

[7]

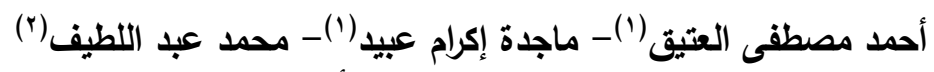 \\ عايدة عبد الغتي حسن أحمد عاديد

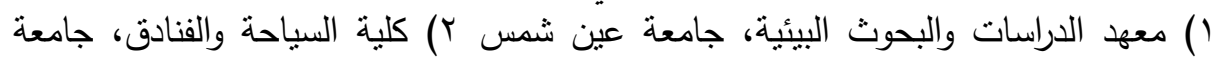

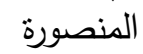

\section{المستخلي}

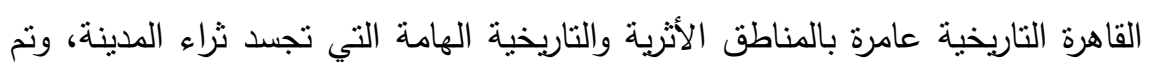

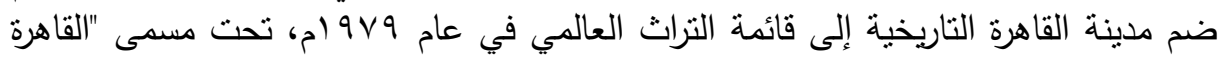

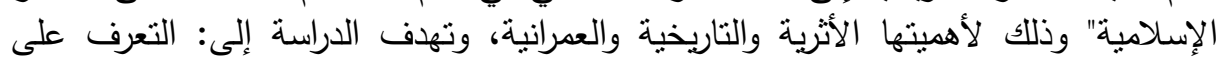

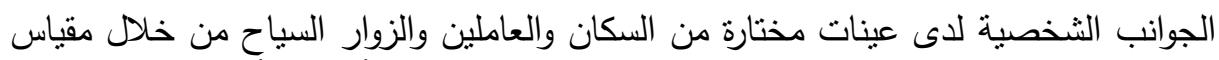

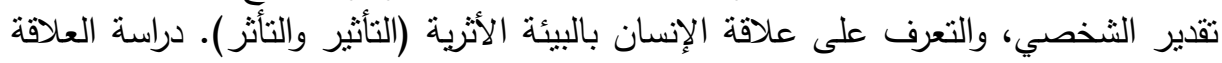

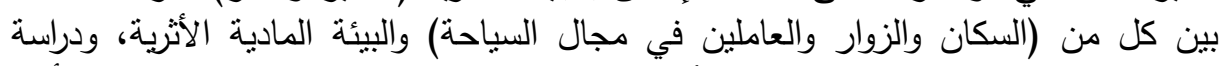

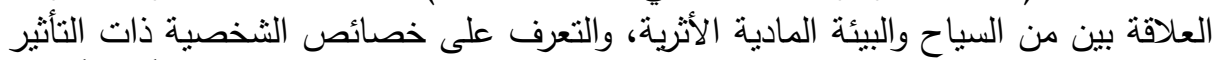

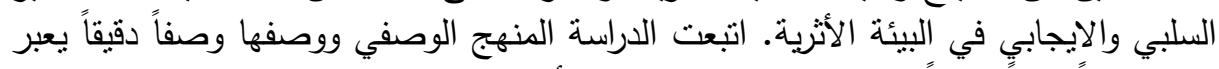

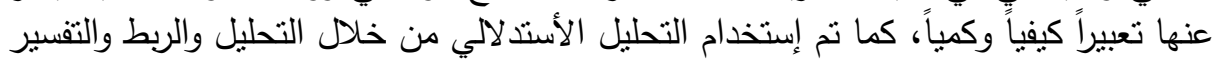
للوصول إلى إستتناجات الدراسة.

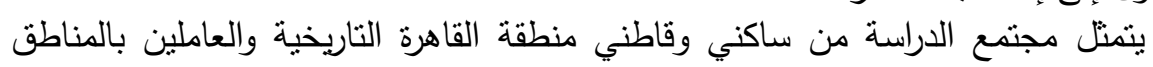

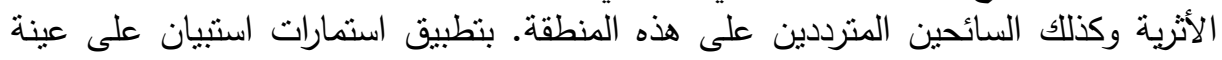

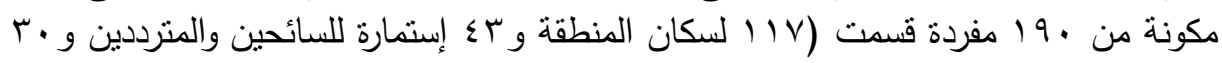

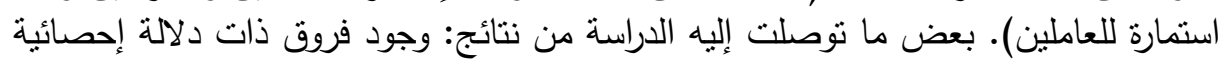

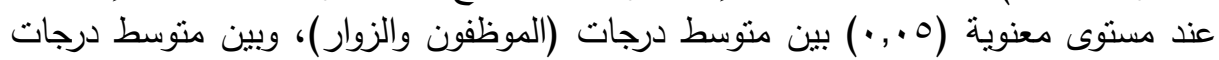

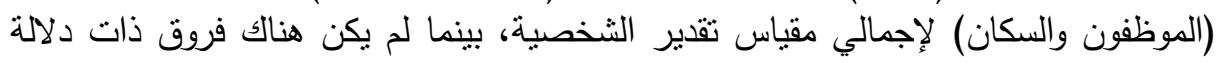

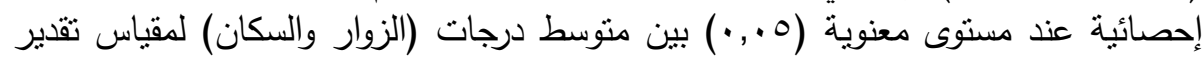

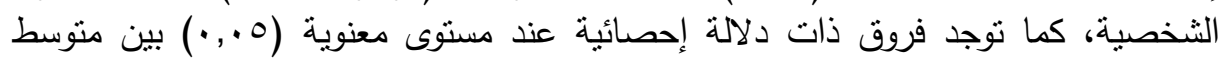
درجات عينة الدراسة (الموظفون والسكان) لكل من (درجة الاهتمام بالأثر والمحافظة عليه،

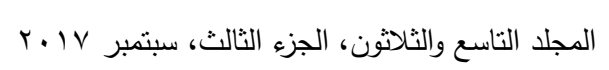


مدى تشويه الأثر ، استخدام الأثر في نشاط اقتصادي أو تجاري أو صناعي، الاهنمام بالحي

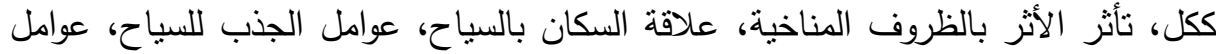

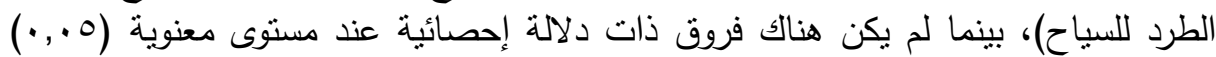

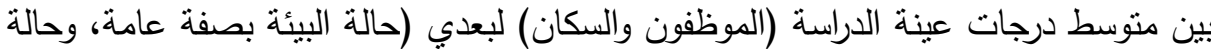
السكان النفسية، لإدراك قيمة الأثر ).

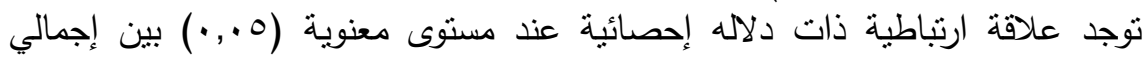

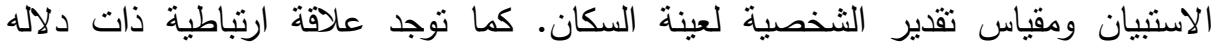

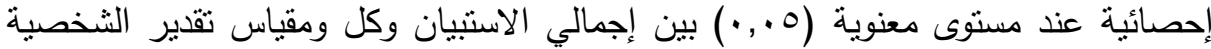

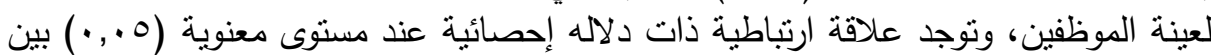

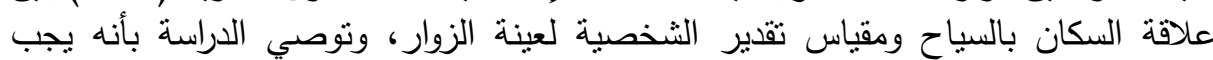

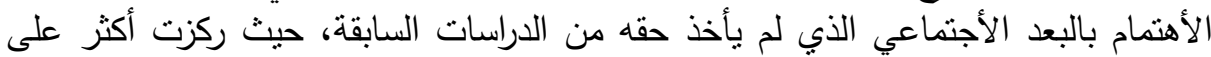

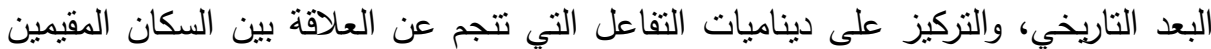

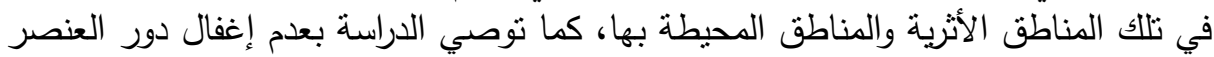

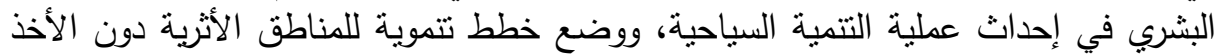
في الأعتبار مواقف وتصورات السكان المحليين المقيمين في تلإنك المناطق، عدم إغفال دور السلوك الإنساني وتفاعله مع تللك المناطق الأثرية.

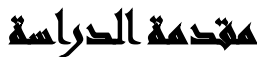

تعد مدينة القاهرة التاريخية احد ابرز المدن التراثية القديمة على مستوى العالم حيث تم

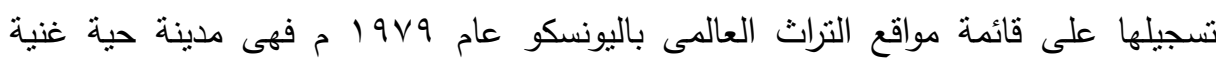

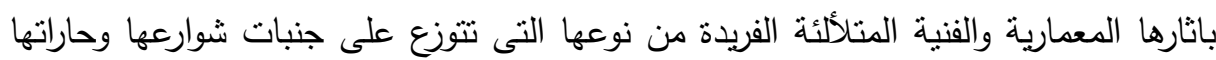

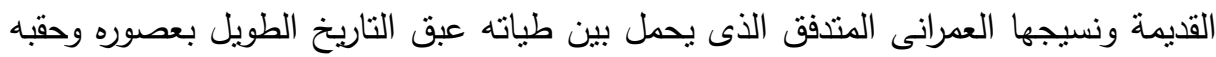
الزمنية المختلفة بدءا من العصر الرومانى حتى عصر اسرة محمد على مما جعلها عاصمة

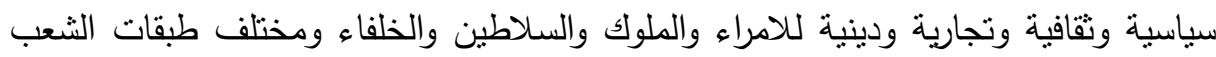

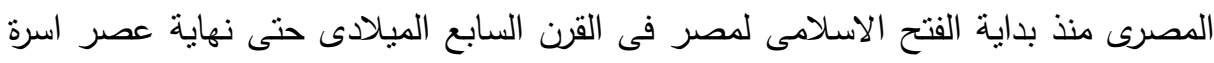
محمد على بمنتصف القرن العشرين الميلادى فظلت طوال هذه الفترة مسيطرة على أقاليم

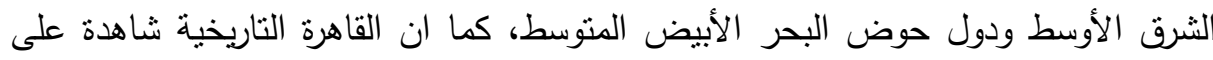

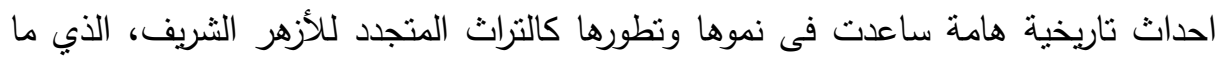


زال يؤدى دوره كمركزاً دينياً وثقافيا وأكاديمياً رائداً للعالم الإسلامي، منذ تأسيس الجامع فى عام

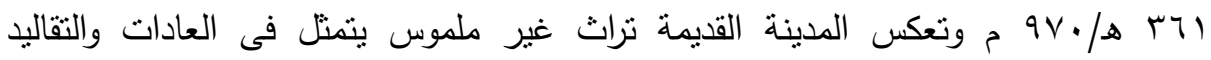
الموروثة عبر الاجيال والاسواق القديمة والحرف التقليدية والاحتفالات والفعاليات الدينية بالأضرحة والمقامات كموالد الائمة والاولياء والطقوس الثعبية كالتراث الثفهى وفنون الرواة

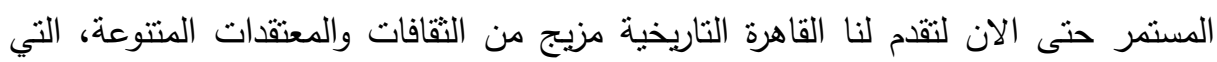
تضيف إلى نراث المدينة العريق. ويثكل التراث ثروة حضارية تمثل قيم وأفكار ومعتقدات وعادات وتقاليد شعوب، ويعد

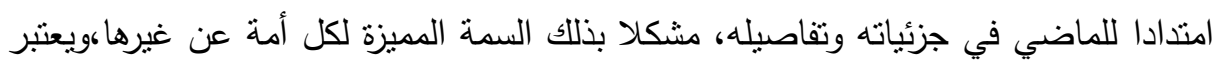
المورث الأثري الثاهد الأساسي على مجمل النشاطات الفكرية والتاريخية، والعلمية، أو قيم روحية التي حدثت في حقبة من زمن ما.

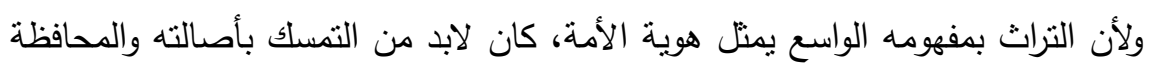

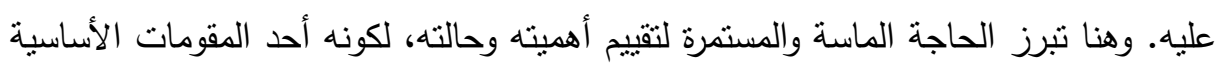

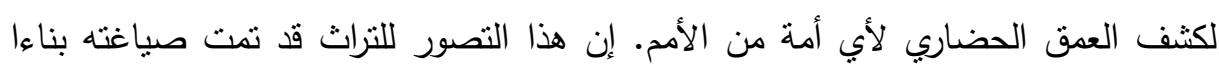

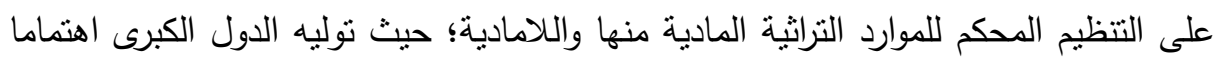
وعناية خاصة في محاولة إستثماره في صناعة السياحة التي شكلت ومنذ العصور القديمة أحد أهم وجوه النشاط الإنساني، بحركات التتقل الوقتية والظرفية التي عرفتها البشرية من مكان إلى في

أما الصعيد الاجتماعي فهي ترتبط ارتبطا وثيقا بالمجتمع حيث يتفاعل السائحون مع

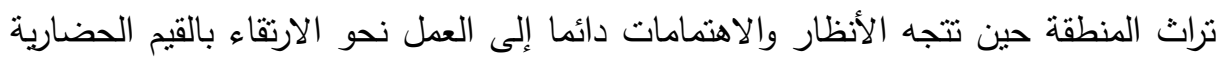
والمعالم السياحية بها وإنشاء معالم أخرى حضارية جديدة لكي نظهر الدولة بالمظهر اللائق بها كدولة سياحية. والقاهرة مدينة عريقة ورثت مواقع مدن قديمة واحتوت مدنا أخرى أحدث، ثم نمت

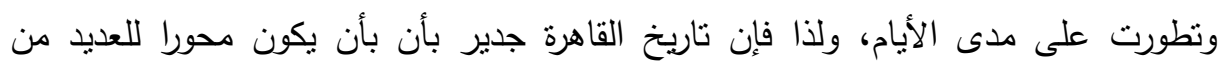

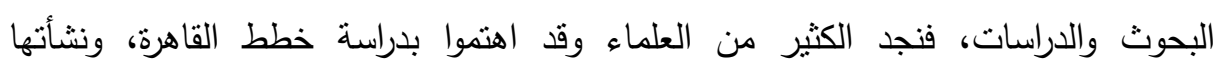


ومعالمها. لذلك فقد احتلت القاهرة مكانا بارزا فى كثير من كتب الخطط مثل كتب ابن دقماق والمقريزى وعلى مبارك الذى أفرد للقاهرة وخططها وآثارها عدة أجزاء من كتابه.

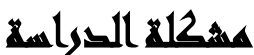

إن المشكلات التي تعاني منها القاهرة التاريخية كثيرة عانت منها هذه المنطقة إلى أن بدأ مشروع "إعادة تأهيل القاهرة التاريخية" الذي تقدمت به منظمة اليونسكو إلى السلطات المصرية

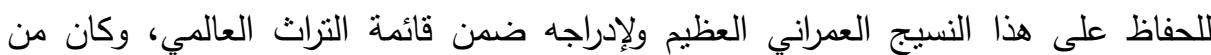
الضروري وضع خطة إستراتيجية لمعرفة وتحليل المشكلات التي تعاني منها منطقة القاهرة التاريخية، ومن ثم وضع خطة الأصلاحات اللازمة. ومن المشكلات التي تعاني منها هذه المنطقة: • ضعف الظروف الأقتصادية والمادية والأجنماعية لسكان المنطقة. • تعاني المنطقة من مشكلات حركة المرور والبنية التحتية والتلوث البيئ. • وجد أن البيئة المبنية لها دور فى إبراز أن الفقر والأمية والبطالة من الأسباب المؤدية

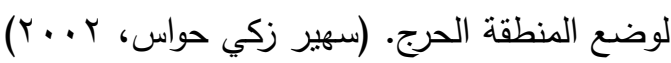

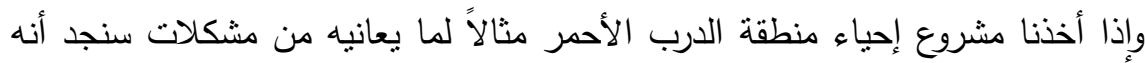

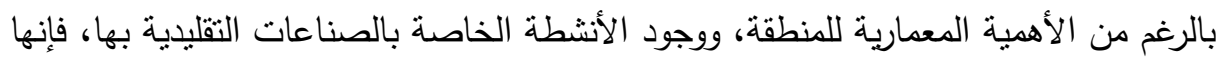

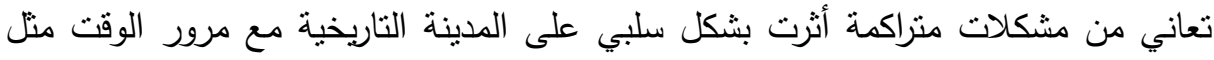

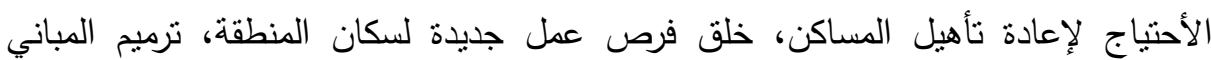
الأثرية التي نأثرت، تحسين البنية التحنية والأماكن المفتوحة، القضاء عادئ على الفقر والأمية، نشر

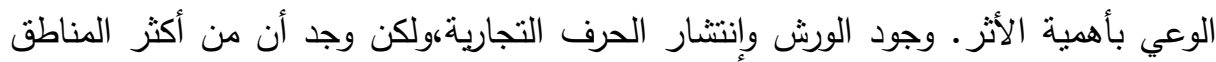
زيادة في وجود نلك الأنشطة هى منطقة الجمالية والموسكي، وهو يعتبر توزيع تاريخي ومكاني للمنطقة، ولكن بالرغم من أثزه السلبي المجتمعي، إلا أنه بدل على قيمة التراث وحيوية المدينة

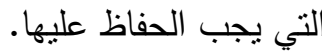


أيضاً من المشكلات التي تعاني منها منطقة القاهرة التاريخية، إستخدام المباني السكنية

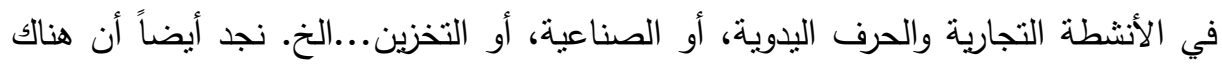
سلوكيات خاطئة لساكني هذه المنطقة رغم أهمية ما بها من آثار هامة في كيفية تعاملهم ومحافظتهم على الأثر • إنعكاس تلك السلوكيات السالبة على علية الجذب السياحي والسياحة

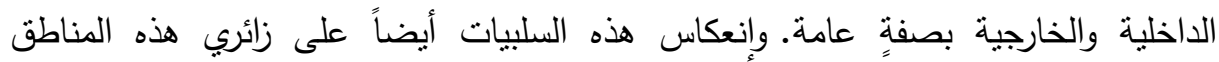

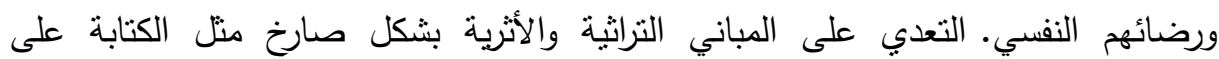
الجدران.عدم الوعي الكافي لقاطني هذه المنطقة بأهميتها التاريخية والأثرية. (تقرير حالة

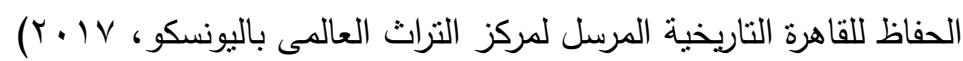

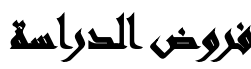

• توجد فروق ذات دلالة إحصائية بين عينة السكان والعاملين في مجال السياحة في الاستجابة على مقياس تقدير الثخصية بأبعاده المختلفة.

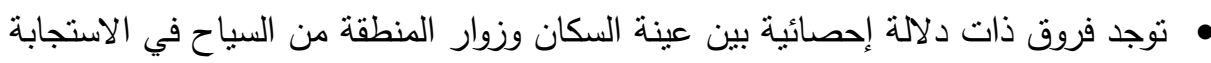
على مقياس تقدير الثخصية بأبعاده المختلفة.

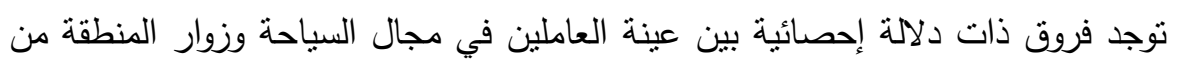
السياح في الاستجابة على مقياس تقدير الشخصية بأبعاده المختلفة.

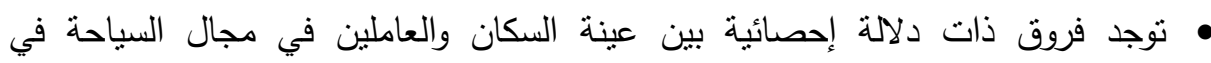
الاستجابة على استبيان "العلاقة بين الآثار والبيئة الأثرية بأبعاده المختلفة".

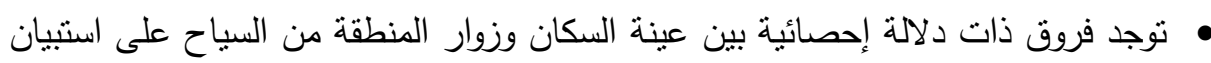
"العلاقة بين الآثار والبيئة الأثرية بأبعاده المختلفة". توجد فروق ذات دلالة إحصائية بين عينة زوار المنطقة من السياح والعاملين في مجال السباحة على استبيان "العلاقة بين الآثار والبيئة الأثرية بأبعاده المختلفة". 


\section{أهمية السوراسة}

يمكن التميز في أهمية الدراسة الراهنة بين جانبين أساسيين: الجانب الأول: الأهمية النظرية حيث تمثل هذه الدراسة جانباً مهماً من جوانب دراسات علاقة الدانة

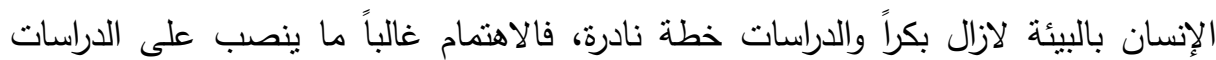
الإنسان ية، بعدها الحيوي دون توضح لعلاقة الإنسان بالبيئة الأثرية والتي تمثل بيئة الإنة مادية وهو جوهر فلسفة علم النفس البيئي والأثر المنبادل بين الإنسان وبيئة الفيزيقية.

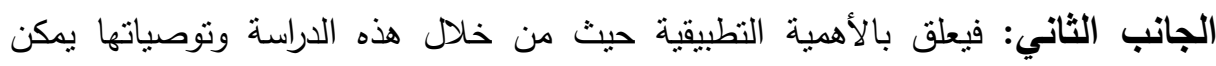

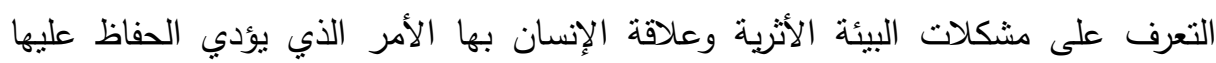

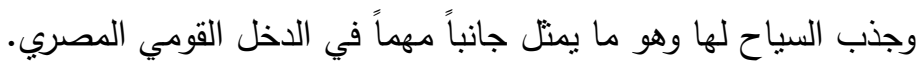

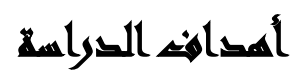

• النعرف على الجوانب الثخصية لاى عينات مختارة من السكان والعاملين والزوار السياح من خلال مقياس نقدير الثخصية.

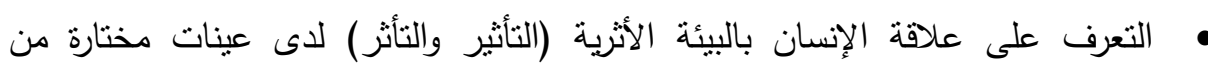
السكان والعاملين والزوار السياح من خلال مقياس علاقة الإنسان بالبيئة الأثرية. • • دراسة العلاقة بين السكان والبيئة المادية الأثرية. • • دراسة العلاقة بين الزوار من السياح والبيئة المادية الأثرية. • • دراسة العلاقة بين العاملين في مجال السياحة والبيئة المادية الأثرية.

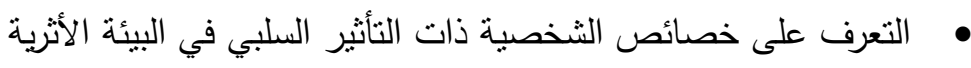
• التعرف على خصائص الثخصية ذات الثأثير الايجابي في البئئة الأثرية.

\section{السراسايت الساريهن}

تقرير برنامج الأمم المتحدة الإنمائي (UNDP) " إعادة تأهيل القاهرة التاريخية": لبرنامج الأمم المتحدة الإنمائي جهاً كبيرا، بالتعاون مع المجلس الأعلى للآثار 
في عامو991، من أجل تعريف استراتيجية متسقة للحفاظ العمراني في القاهرة التاريخية . استتد تحليل الموقع إلى عدة مصادر للمعلومات، مُهيكلة في أريعة قطاعات: •بيانات إحصائية معنية بالظروف الاجتماعية والاقتصادية والسكانية (الديموجرافية) والمادية .تم إجراء تحليل يستتد إلى عدد من المعايير للتعرف على الثياخات (• (1) ذات التهاتيه الظروف الاجتماعية والاقتصادية والمادية التي تحتاج إلى تدخلا تعاجلة. • تقييم المكونات المكانية لبيئة العيش، وشمل النقييم الجوانب الخاصة بالتراث والنسيج العمرانى وتوزيع الأنشطة ومشكلات حركة المرور والبنية التحتية. • • السوق العمرانية :السياحة والإسكان والعمل.

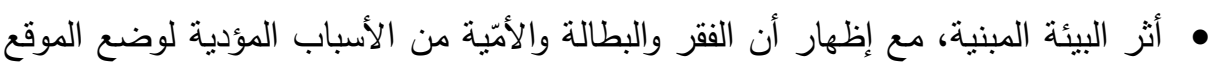

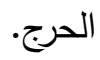
اقترح تقرير برنامج الأمم المتحدة الإنمائي خطة عمل إطارية(FWP) تلقى الضوء على القى الارتباط الضوء على الارتباطين الأنشطة ووسائل النقل والمواصلات والبنية التحتية، كمؤشرات التهات مهمة تؤثر على صورة ممنلك التراث العالمي. دراسة ماجدة عبيد، وأحمد عرفة بعنوان "التنمية المتواصلة، دراسة عن حالة منطقة الجمالية"، r r. r. . وقد قامت هذه الدراسة بهدف تحسين المستوى البيئئ لمنطقة الجمالية وحماية التراث بها، وهذه المنطقة تحنوي على عدد كبير من المباني والآثار التاريخية القديمة.

\section{وقد خلصت هذه الاراسة إلي:}

• ضرورة تحسين الحالة المعيشية لسكان هذه المنطقة وذلك بتوفير المرافق الهامة لهم منل الصرف الصحي الجيد، خدمات الكهرباء وإضاءة الثوارع وخدمات الإتصالات إيجاد حل لهره

$$
\text { للتخلص من القمامة.......وغيرها. }
$$

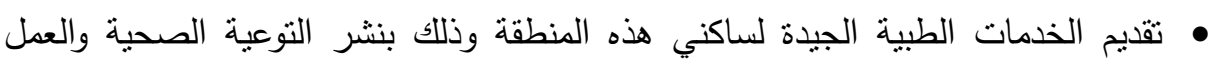
على التقليل من معدلات التلوث في هاه المنطقة.

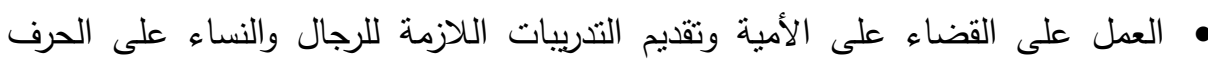
التقليدية وتدريبهم على إستخدام الكمبيوتر - 
• تحسين حالة الطرق والمرافق العامة والعمل على تطوير المنطقة عمرانياً وذلك عن طريق

ترميم المباني الأثرية المتضررة.

دراسة أحمد الجلاد بعنوان "قضايا ومشكلات التنمية البيئية بالمناطق الأثرية السياحية "دراسة ميدانية عن القاهزة الفاطمية"، ب . .ب. تتاولت هذه الدراسة الأسباب الحقيقية وراء المشكلات البيئية في المناطق الأثرية بالقاهرة، والتي تعود إلى الضغنه الضوط والمشكلات

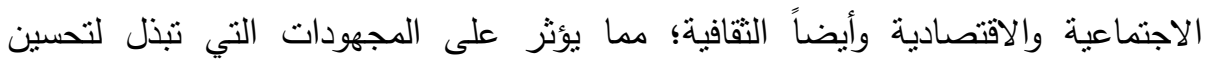
الأوضاع البيئية للمنطقة، والتي تؤثر بالتالي على المنطقة الحضارية والأثرية. وقد رأت هذها

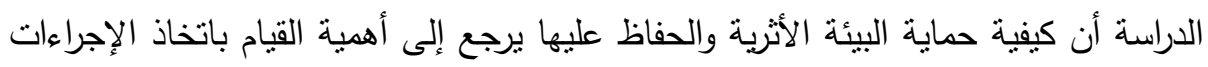
القانونية لضبط استخدام الأساليب التكنولوجية البيئية، كذلك العمل على نشر التوعية البيئة والعمل على تغيير السلوكيات الخاطئة بين الأفراد قاطني تلك المنطقة، كذللك نقل الأنشطة لهنة التجارية التي تؤثر على المكان بيئياً ولا تخدم السائحين والزائرين للمنطقة، أيضاً حل مشاكل الصرف الصحي والمياه الجوفية التي تؤثر تأثيراً مباشراً على المنطقة الأثرية وساكنيها. دراسة سهير زكي حواس عن المجتمع المدني مسويلاً ومستفيداً، وقد جاءت هذه الدراسة في الباب الثاني من كتاب "الحفاظ العمراني وإحياء المناطق التراثية في مصر"تطبيقاً على

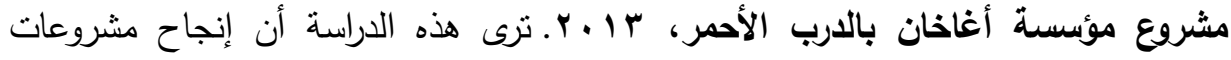

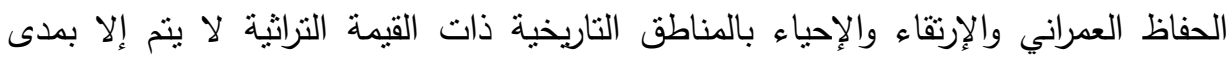

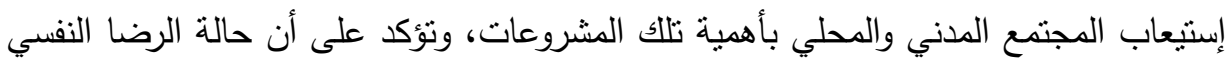

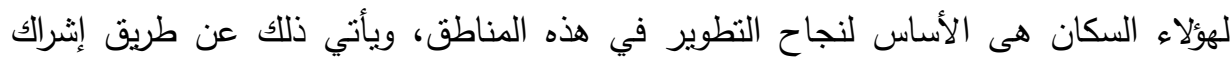
الأهالي في مراحل المشروعات للحفاظ والإرتقاء بالمنطقة. الاراسة الثانية عشرة الصادرة عن اليونسكو قُدمت في "مشروع إحياء القاهرة

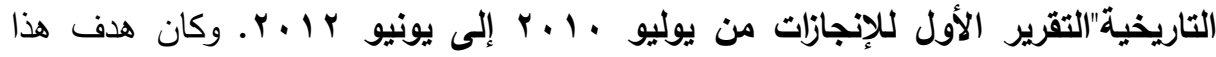

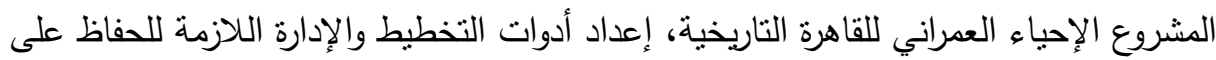
قيم التراث. وقد جاء في الفصل الرابع من هذا التقرير تحت عنوان"دراسات أولية متخصصة 
وقد خلصت هذه الاراسة إلى:

• أن نقص الوعي العام والمجتمعي يعتبر نقطة هامة جداً بالنسبة للسكان وقاطني تلكا

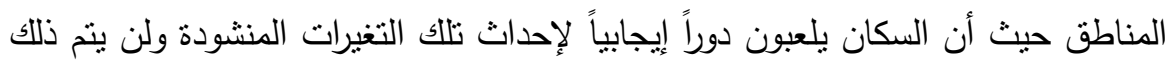

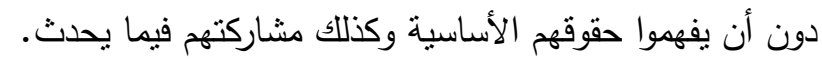
• توفير برامج محو الأمية للرجال والنساء، كذللك توفير أماكن للاعم التعليمي لأطفال المدارس فإن ذلك سيؤدي إلى رفع مستوى المعيشة للسكان. • تحسين جودة الرعاية الصحية في المراكز الصحية العامة على المستوى المحلي. • إعادة تأهيل شبكات المياه والكهرباء والصرف الصحئ. هث الحكومات والهيئات المسؤلة على وضع خطة صيانة مستدامة لهذه الخدمات لضمان ولهيان مستوى أداء أفضل لتلك المرافق والخدمات. دراسة هيئة التخطيط العمراني بعنوان "مشروع تتمية القاهرة الفاطمية وشارع المعز" ويتتاول هذ المشروع والذي قمت به هيئة التخطبط العمراني نطوير منطقة شارع المعز ومنطقة القاهرة الفاطمية كلاً على حده.

مشروع تطوير القاهرة التاريخية: ويقوم على تحديد المنطقة ناريخياً وتحليل لهنطقة القاهرة التاريخية منل حالة المباني وارتفاعها ومدى حالة التذهور العمراني بها كذلك كيفية

$$
\text { استخدام الأراضي كمناطق تجارية - سكنية - حرفية وخدمية. }
$$

وقد خلص هذا المشروع إلي تننى إستراتيجية عمرانية لتنبي خدمات المنطقة وتحسينها ورفع مستوى معيشتها. مشروع شارع المعز : قد اعتمدت هذه الدراسة على توصيف هذا الثارع من الناحية الأثرية وأيضاً أهميته من الناحية التاريخية فهو يمثل عصب المدينة منذ نشأتها فهو يحتوي هن هن على مجموعة هائلة من المباني الأثريه. وقد خلصت هذه الدانه الدراسة إلى:

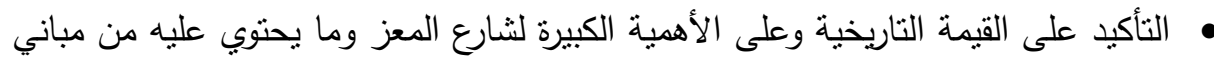
أثرية عظيمة. 
• أيضاً قيمته الاجتماعية والثقافية والسياحية فهو يعتبر من أهم المزارات على الخريطة السياحية للآثار الأسلامية. هذلك قيمته التجارية لما يحتوي عليه من حرف يدوية وأنشطة تجاريه تهم وتخدم السائحين وغير السائحين.

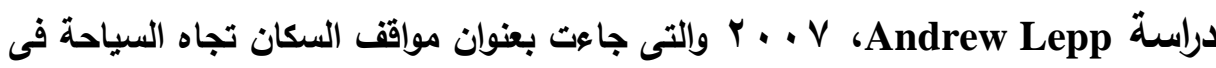
بيجودي فى أوغندا، وهدفت الدراسة إلى التعرف على مواقف السكان المحليين تجاه السياحة

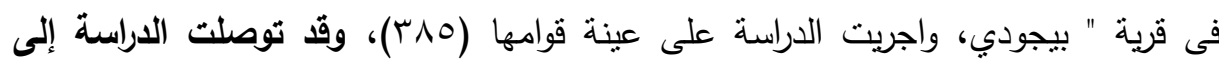

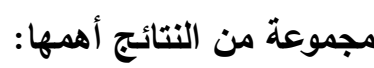
• توجد أتجاهات ايجابية لدى السكان المحليين تجاه السياح والسياحة فى قرية بيجودي، ونجمت هذه الأتجاهات الايجابية نتيجة أعتقاد السكان المحليين أن السياحة تعمل على تلى لتهاه

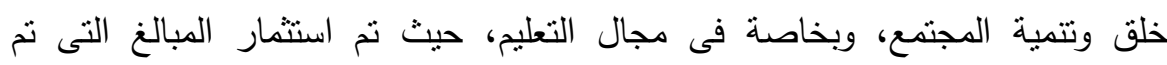
الحصول عليها من السياح فى أنثاء أول مدرسة ابتدائية فى قرية بيجة وليجودي.

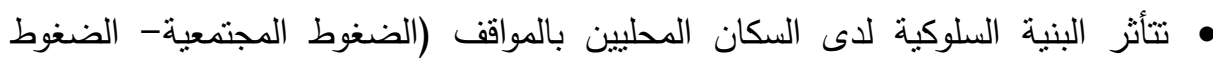
المادية) وكلاهما يتأثز بالمعتقدات. • هناك عدة آليات تسهم فى تبني السكان المحليين أتجاهات ايجابية تجاه السياحبة والسياح ومنها : • المشاركة فى صنع القرار، نوع السياح، الاعتماد الأقتصادي على السياحة، درجة الثقافة بين المقيمين والسياح. • تلعب الفوائد والمنافع الأقتصادية دورا كبيرا فى مواقف السكان المحليين المقيمين فى لئ المناطق السياحية تجاه السياح.

L. Wakiuru Wamwara-Mbugua1 and T. Bettina Cornwell دراسة والتى جاءت تحت عنوان: تأثير السياحة على البيئة فى ماليندي، كينيا، وهدفت هذه الدراسة إلى التعرف على الاثار الاجتماعية والثقافية والاقتصادية للسياحة فى ماليندي بكينيا، 
وتوصلت الدراسة إلى مجموعة من النتائج ومنها:

- تمر عملية السياحة فى ماليندي بكينيا بالمراحل التالية:

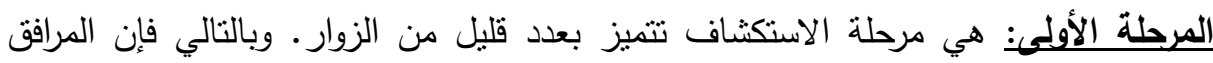

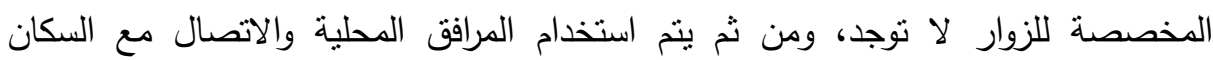

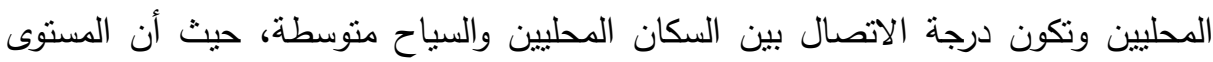

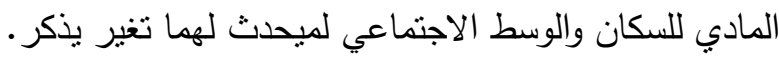
المرحلة الثانية: هي مرحلة المشاركة، والمضيف المجتمع يستجيب لعدد متزايد من السائحين من خلال البدء في توفير التسهيلات في المقام الأول أو حتى حصرالسائحين. وترتفع درجة التفاعل بين السكان المحليين وبين السائحين، وتبدأ عملية الترويج السياحي من قبل التبل الثركات

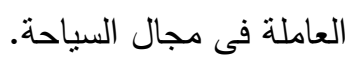
المرحلة الثالثة: هي مرحلة التطوير التي يمتل منطقة سوق سياحية محددة جيدا وهذا هو التي

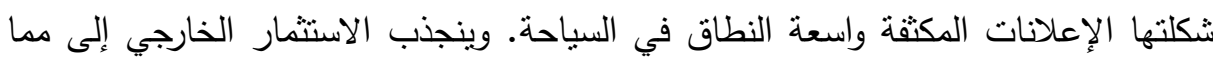

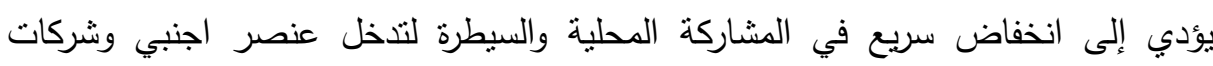
متعددة الجنسيات فى مجال السياحة الامر الذي يهمش من دور التئس السكان المحليين. وتحل المنظمات الدولية محل المرافق المحلية. هناك تغييرات ملحوظة في والمظهر المادي للمنطقة والثقافية وتنتكمل مناطق الجذب الطبيعية من صنع الإنسان المرافق المستوردة.

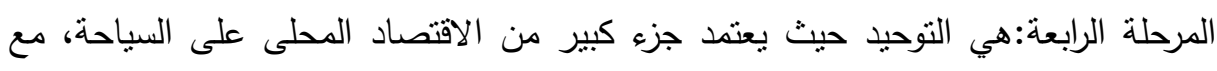
وجود ارتفاع منزايد فى معدلات السياح.

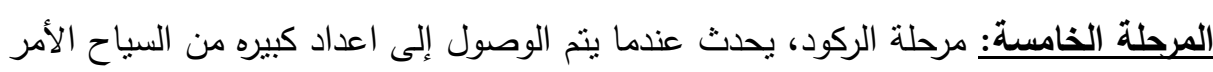
الذى يترتب عليه مشاكل بيئية ومشاكل اجتماعية وثقافية . المرحلة السادة: هي الانخفاض، وخلال هذه المرحلة تتخفض اعداد السياح ويقل الاعتماد على صناعة السياحة وتزيد المشاركة المحلية، وتفقد المنطقة السياحية وظيفتها تماما. المرحلة السابعة: هى مرحلة التجديد ويتم خلال هذه المرحلة تغيير شامل لهناطق الجذب ونب السياحي. 
هناك تغير فى القيم الثقافية والاجتماعية وبخاصة فى المرحلة الثانية والثالثة حيث يزيد معدل التفاعل بين السياح والسكان المحليين الامر الذي ينجم عنه أكتساب بعض والئه القيم الثقافية وتغير البعض لدى السكان المحليين.

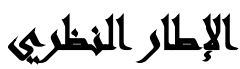

الإنسان الحضري

منطقة القاهرة التاريخية

عوامل الجذب والطرد للسائحين
• • • - ديناميات التفاعل بين الإنسان والبيئة

$$
\text { • • الحيز الأثري ل السلوكيات المجتمعية }
$$

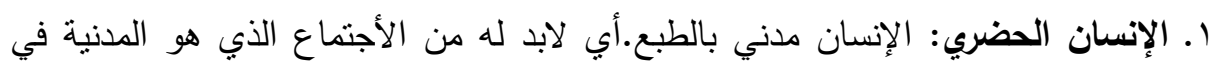

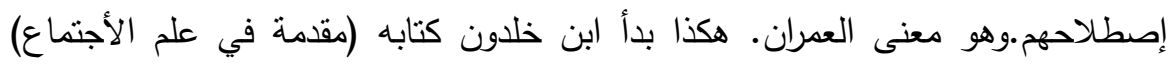
فالإنسان يميل بطبيعته إلى التحضر ، وقد بدأت ملامح التحضر في مصر منذ العدان العصور

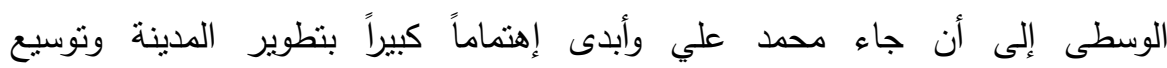
نطاقها،فالإنسان الحضري يسعى دائماً إلى إشباع حاجاته الأساسية.

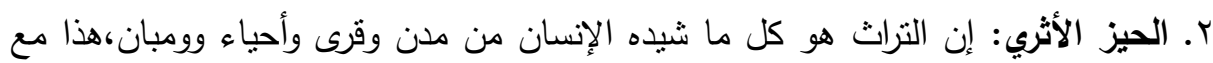

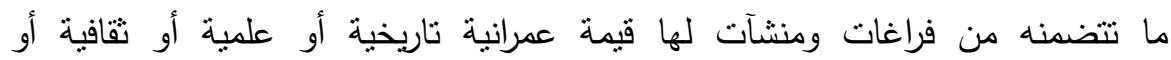

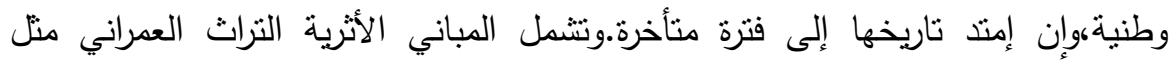

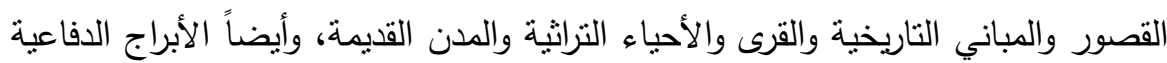

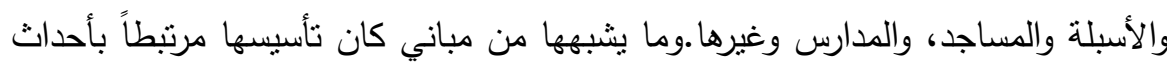
تاريخية ودينية أو سياسية وأقتصادية واجنماعية،أو كان إنثائها يعكس نمطاً أو طرازاً في في وني

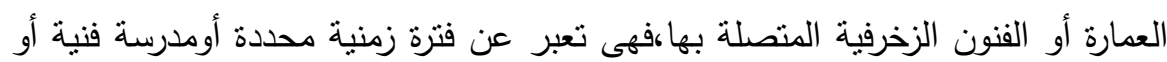
حضارة تاريخية لها جغرافيا معينة. إن البنية الحضرية الأثرية هى التي تعطي خصائص شكلية لفهم الإنسان لبيئته الطبيعية

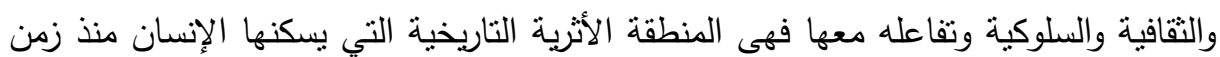
بعيد والتي أعناد عليها. 
r. منطقة القاهرة التاريخية: تقسم القاهرة التاريخية إلى عدة مناطق هي: حي الجمالية باب الوزير - الفسطاط (مصر العتيقة).

ـ. السلوكيات المجتمعية: الإنسان بطبيعته كائن إجتماعي فهو لا يعتبر كائناً بيولوجياً يحيا

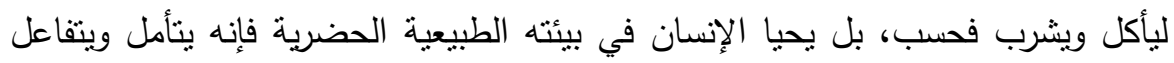
مع البيئة المحيطة به.وعندما يحيا في بيئة مضطربة خالية من النظام والتوافق والأنسجام تمتلئ نفسه بالكآبة والخوف،على عكس بهل وإن كانت البيئة منظمة وبها جذب سياحي ونشاط ثقافي يصبح ذو نزعة تفاؤلية. ه. عوامل الجذب والطرد للسائحين: تمثل القاهرة التاريخية روعة من روائع العقل البشري،

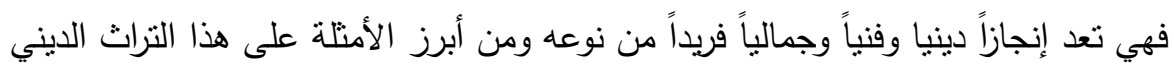

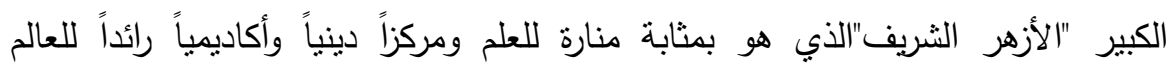
الإسلامي السني منذ تأسيسه في عام • و وم،أيضاً مسجد أحمد بن طولون بمئنتنه الملتوية الرائعة، وغيرها من المساجد والأضرحة الهامة لأولياء الله الصالحين.

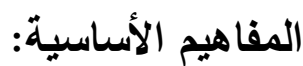

1. المفهوم التاريخي: تعد القاهرة التاريخية من أقدم وأهم المدن على مر العصور، وقد

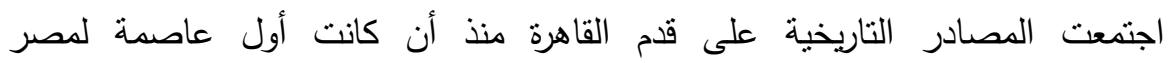
كانت (أون) بأرض النعام بالمطرية، ثم مدينة حري عا (حري رع حا) ومعناها ميدان القتال وكان ذلك عام هبr باق.م، وكانت تقع مكان مصر القديمة والتي حلت قلعة بابليون

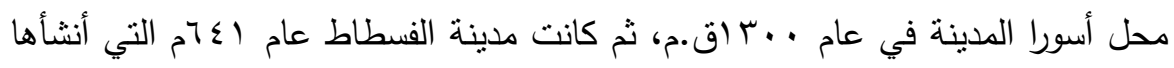
عمرو بن العاص والتي أتخذ أسمها من خيمة عمرو التي اقام بها وسط معسكره. ثم

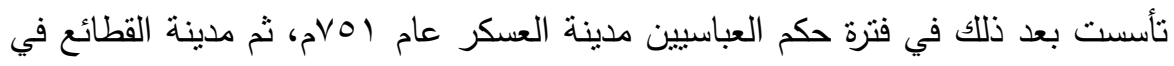

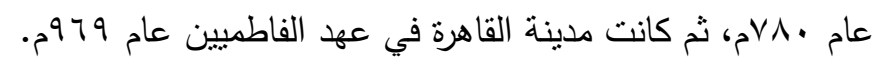

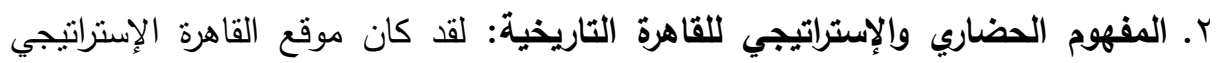

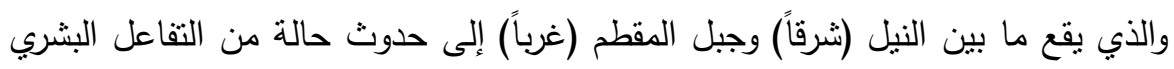

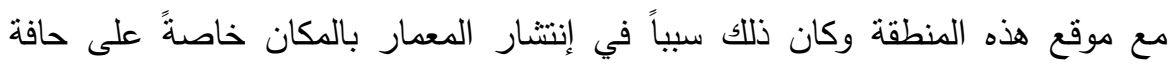

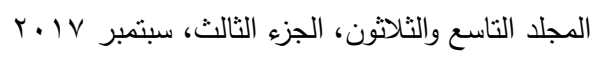


الدلتا، كذللك أدى (مجرى العيون) الذي يعود تاريخه للعصور الوسطى إلى ربط المدينة

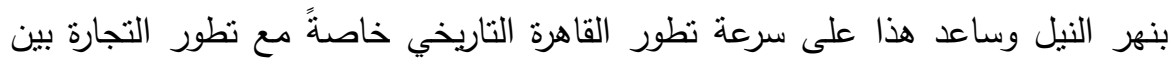

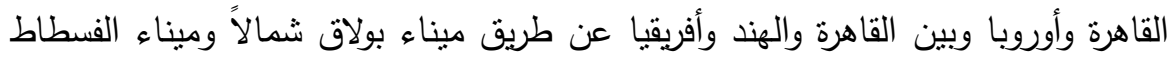
جنوباً وساعد ذلك على زيادة النبادل الثقافي والحضاري ما بين مصر والبلدان الأخرى.

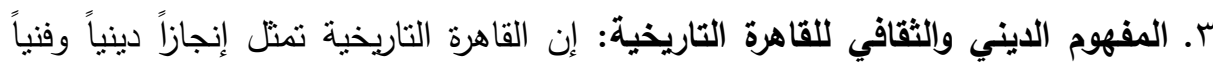

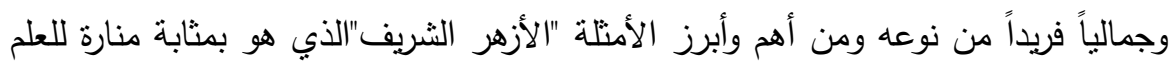

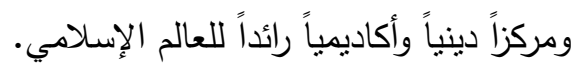

\section{إجراكاهي التصراسة}

منهج الاراسة: اتبعت الدراسة المنهج الوصفي حيث يلائم موضوع الدراسة والذي يعتمد على دراسة الظاهرة كما نوجد في الواقع ويتم وصفها وصفًا دقيقًا ويعبر عنها تعبيرًا كيفًاً

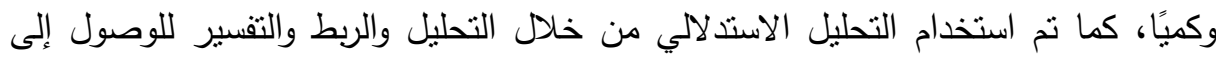
استتناجات لبناء التصور المقترح ولتزويد البحث بالمعلومات والمعارف، وقد استخدم الباحث

$$
\text { مصدرين للحصول على المعلومات اللازمة للدراسة. }
$$

مجتمع الاراسة: يتمثل مجتمع الدراسة من ساكني وقاطني منطقة القاهرة التاريخية والعاملين بالمناطق التاريخية وكذللك السائحين المترددين على هذه المنطقة محل الدراسة. عينة الاراسة: نم سحب عينة عشوائية تتمنل في ساكني وقاطني منطقة القاهرة التاريخية وكذلك السائحين المترددين على هذه المنطقة وذلك بتطبيق استمارات استبيان على عينة

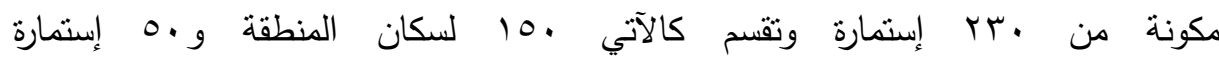
للسائحين والمترددين و • ب استمارة للعاملين بالمنطقة.

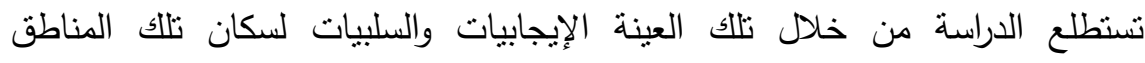
وسلوكياتهم وأيضاً عملية التأثير والتأثر المتبادل ما بين السكان وبين المباني الأثرية التي لإينابيات 


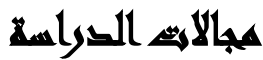

المجال الموضوعى: دراسة الإيجابيات والسلبيات لسكان نلك المناطق وسلوكياتهم وأيضاً

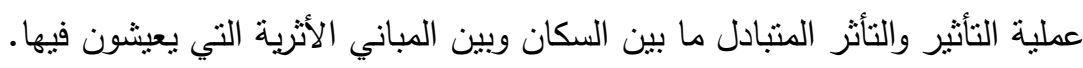
المجال المكانى: قامت الباحثة باختيار منطقة القاهرة التناريخية.

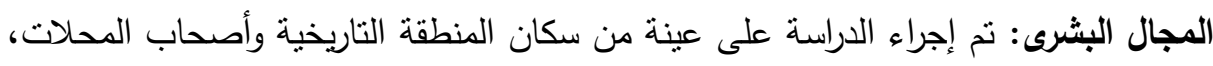
والعاملين بالمنطقة التاريخية والسائحين وقد استغرق تطبيق الاستمارات ثلاثة أسابيع.

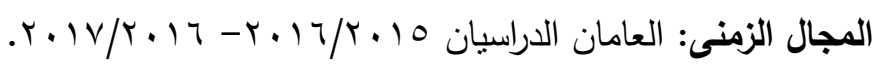

\section{أتوايت التوراسة}

سوف تعتمد أدوات جمع البيانات لهذه الدراسة على: الدراسة الوصفية التحليلية التي

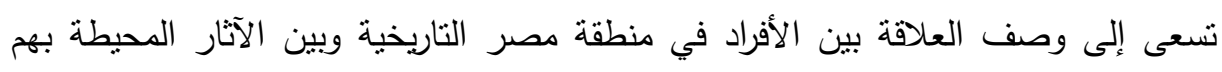
والتي يسكنون بداخل مبانيها وكيفية تعاملهم معها. تعتمد الدراسة على الدراسة الأستقصائية التحليلية الخاصة بأهالي المنطقة وسوف يتم ذلكاني

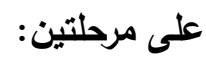
الأولى هي مرحلة البحث الدكتبي عن طريق إستخدام المراجع العلمية والدقالات والأبحاث والدوريات في هذا المجال.

الثانية هي مرحلة البحث الميداني عن طريق تجميع البيانات والمعلومات من الواقع من خلال زيارات ميدانية للمنطقة هدف الدراسة عن طريق إستيان باللغتين العربية والإنجليزية لنطبيقه على الأهالي والسائحين بالمنطقة. وتمثلت أدوات الدراسة في أداتين هما:

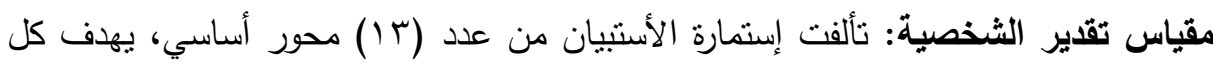

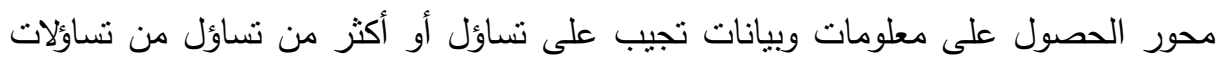
الدراسة لتحقيق الأهداف البحثية للاراسة 
استمارة الأستبيان: هو أداه للتقرير الذاتي أعدت بهدف الحصول على تقدير كمي لكيف يرى

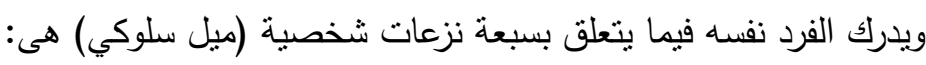

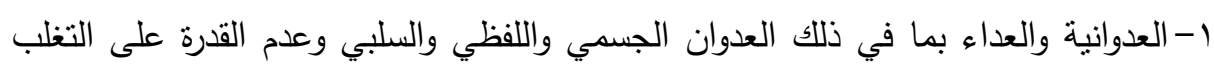
على مشاعر العداء والكراهية تجاه الأخرين.

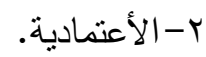

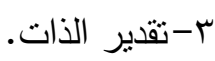
ع - الكفاية الثخصية.

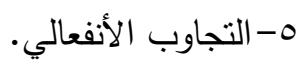

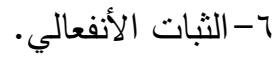
V- النظرة للحياة.

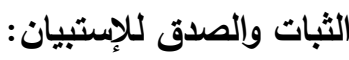
ثبات الاستيبان: للتحقق من ثنات الاستبيان استخدمت الباحثة معادلة ألفا كرونباخ (CronbachAlpha) وتبين أن معاملات الثبات الناتجة باستخدام هذه المعادلة جميعها قيم

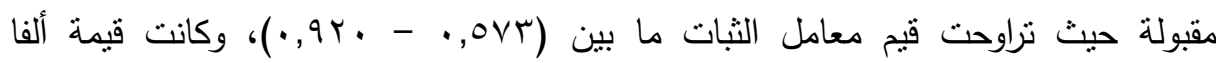

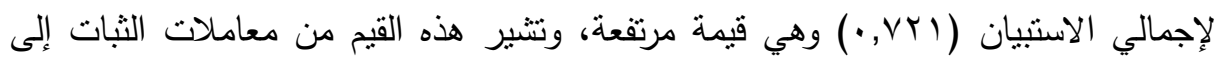

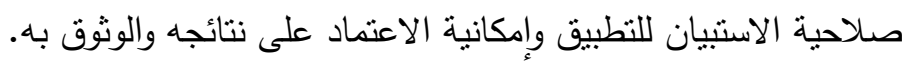
صدق الإتساق الداخلي للاستيان: نم حساب معاملات ارتباط كل بعد من أبعاد الاستبيان بالدرجة الكلية للاسنبيان والتي نتجت عن تطبيق الاستبيان على عينة مبئية، وقام الباحثون

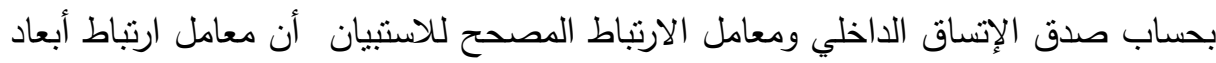

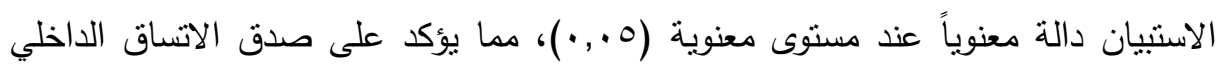

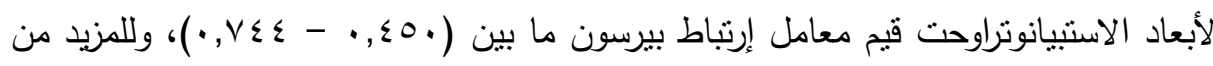

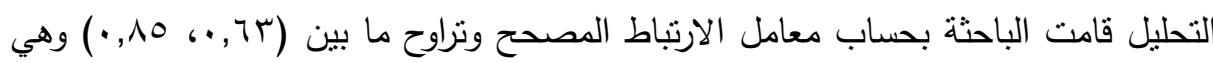
قيم تؤكد على صدق الاستبيان. 


\section{تئائج السواسمة}

جدول(1): اختبار ت T-Test لحساب الفروق بين منوسط درجات عينة الدراسة (الموظفون والسكان) لأبعاد مقياس تقدير الثخصية

\begin{tabular}{|c|c|c|c|c|c|c|}
\hline \multirow{2}{*}{ 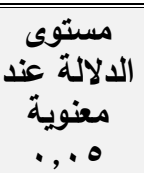 } & \multirow[b]{2}{*}{ قيمة } & \multicolumn{2}{|c|}{ السكان (ن= = الن II ) } & \multicolumn{2}{|c|}{ الموظفون (ن= . r } & \multirow[b]{2}{*}{ المتغيرات } \\
\hline & & | الانحراف & المتوسط & الالمعياري & المتوسط & \\
\hline غير دالة & $1, \vee \vee 99$ & $\overline{r, \Lambda . ~}$ & rY,Yq & $\bar{r} r, \mu \tau$ & $\overline{T r}, \Psi V$ & النظرة السلبية للحياة \\
\hline دالة د د د & $\varepsilon, V V$ & $r, \wedge q$ & 19,10 & $Y, Y V$ & $r Y, \cdot V$ & عدم الثنات الإنفعالي \\
\hline غير دالة & $1, V Y Y$ & $T, V V$ & 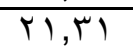 & $r, \ldots$ & $r Y, r$. & عدم التجاوب مع الآخرين \\
\hline غير دالة & $\cdot, \cdot 1 \leq$ & $V, O H$ & $\varepsilon Y, \leqslant 0$ & $\Gamma, \Sigma \Gamma$ & $\varepsilon Y, \varepsilon r$ & تقويم الذات \\
\hline غير دالة & 1,179 & $\varepsilon, Y \mu$ & YI,OY & $r, 91$ & $r \cdot, \varepsilon \cdot$ & أ- عدم الكفاءة الشخصية \\
\hline غير دالة & 1, & $\varepsilon, 19$ & $r \cdot, q r$ & $r, V q$ & $r r_{,} \cdot r$ & ب- النقدير السلبي للذات \\
\hline دالة & $0, Y \leq$ & $r, q$. & YT,O. & $r, 74$ & YY,OV & الإعتمادية \\
\hline دالة & $\varepsilon, \varepsilon Y q$ & $\mu, 7 \mu$ & $Y \mu, Y \mu$ & $r, 11$ & $r\rceil, \varepsilon r$ & العدوان/العداء \\
\hline دالة & r,qAr & $1 \leq, Y_{O}$ & $10 r, 0 \leq$ & 7,10 & $17 \pi, 1 \mathrm{~V}$ & ى ىقية مقياس تقدير \\
\hline
\end{tabular}

من الجدول السابق لحساب الفروق يتضح الآتي:

> وجود فروق ذات دلالة إحصائية بين منوسط درجات عينة الدراسة (الموظفون والسكان)

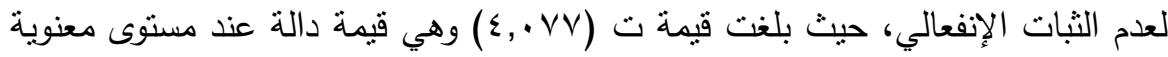

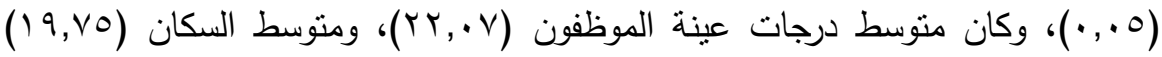
لصالح عينة السكان.

\& وجود فروق ذات دلالة إحصائية بين منوسط درجات عينة الدراسة (الموظفون والسكان)

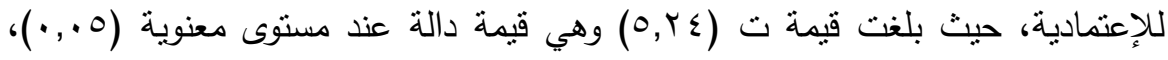

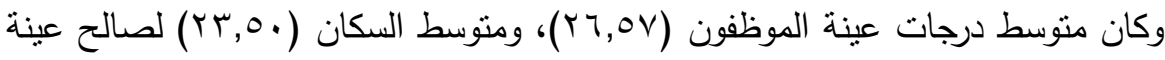

ك وجود فروق ذات دلالة إحصائية بين منوسط درجات عينة الدراسة (الموظفون والسكان)

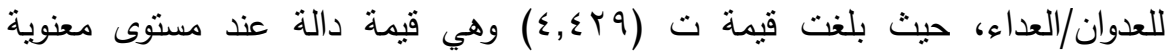




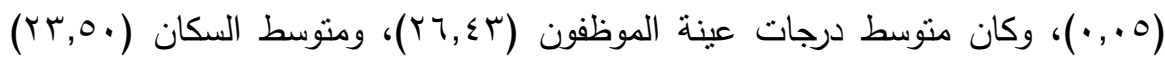
لصالح عينة السكان.

ه وجود فروق ذات دلالة إحصائية بين منوسط درجات عينة الدراسة (الموظفون والسكان)

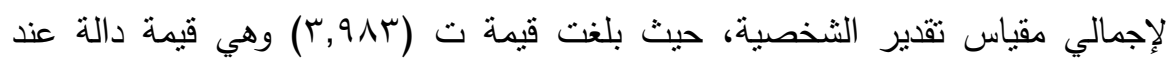

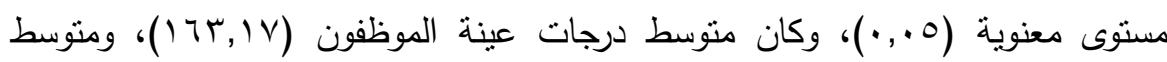

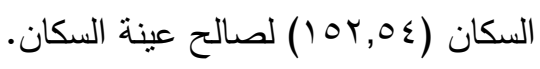

Strickland-Munro, J.K. , Moore, S.A. and وهو ما أنشارت له دراسة Freitag-Ronaldson, S المجتمعات المجاورة لحديقة كروجر الوطنية فى جنوب أفريقيا، وهدفت الدراسة إلى أستكثاف تاني

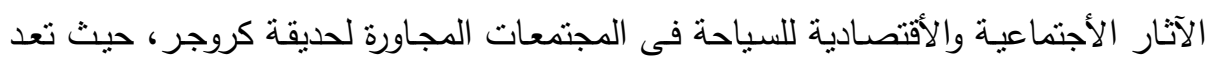
هذه الحديقة الوطنيـة الرئيسية في جنـوب افريقيـا، كمـا يشـعر كثيـر مـن السكان المحلينين

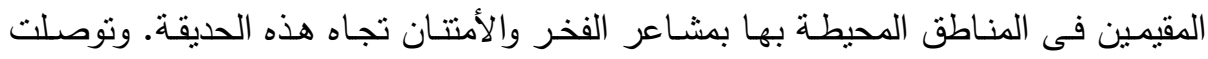
الدراسة إلى مجموعة من النتائج ومنها: ه هناك أثنار ايجابية كبيرة ناجمة عن تأثثر السياحه على المجتمعات المحلية المحيطة بحديقة كروجر، على الرغم من قلة المنافع الاقتصادية الا أنها موجودة.

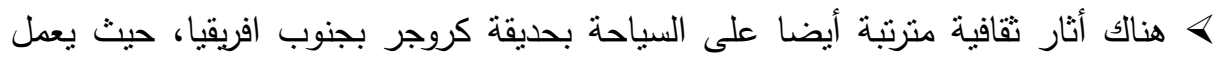

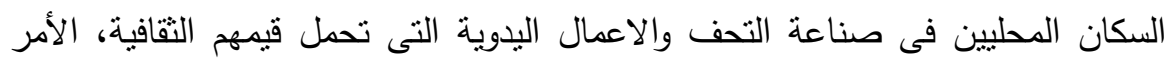
الذى يمنل بالنسبة لهم إحياء للتراث ونشر لنقافتهم المحلية. ه يشعر السكان المحليين بالاغتراب فى أغلب الاحبان، نتيجة عدم المساواة فى توزيع الدخل وفرص العمل فى مجال السياحة. 
جدول(ץ): اختبار ت T-Test لحساب الفروق بين متوسط درجات عينة الدراسة (الزوار والسكان) لأبعاد مقياس تقدير الثخصية

\begin{tabular}{|c|c|c|c|c|c|c|}
\hline \multirow{2}{*}{ عند معنو الدلالة } & \multirow{2}{*}{ قيمة } & \multicolumn{2}{|c|}{ السكان (ن= I IV) } & \multicolumn{2}{|c|}{ الزوار (ن= = ع } & \multirow[b]{2}{*}{ المتغيرات } \\
\hline & & الالمعياري & المتوسط & الالمعياري & المتوسط & \\
\hline غير دالة & $1, \vee 0$. & $r, \wedge$. & rr, rq & $r, \varepsilon$ & rr,19 & النظرة السلبية للحياة \\
\hline غير دالة & • & $r, \wedge q$ & 19,10 & $r, 09$ & 19,90 & عدم الثبات الإنفعالى \\
\hline غير دالة & $\cdot, \cdot 1 \cdot$ & $Y, V V$ & YI, M & r & YI, r. & عدم التجاوب مع الآخرين \\
\hline غير دالة & $1, \vee \vee r$ & $\varepsilon, Y T$ & Y1,0r & $r, r q$ & $r \cdot, Y T$ & أ- عدم الكفاءة الثخصية \\
\hline غير دالة & $\cdot, Y V \cdot$ & $\varepsilon, 19$ & $r \cdot, q r$ & $7,1 V$ & $Y 1,17$ & ب- التقدير السلبي للذات \\
\hline غير دالة & $\cdot, V \leq r$ & $V, 0 T$ & $\leqslant Y, \leqslant 0$ & 1,01 & $\Sigma 1, \Sigma Y$ & تقويم الذات \\
\hline غير دالة & $\cdot, \Sigma \cdot \Sigma$ & $r, q$. & rT,O. & $r, r q$ & $r r, V Y$ & الإعتمادية \\
\hline 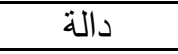 & $r, r \wedge 0$ & r,7r & Tr,YT & $\varepsilon, \Gamma$. & YI,TV & العدوان/العداء \\
\hline غير دالة & $\cdot, \leqslant \wedge 7$ & $1 \leqslant, Y O$ & lor, os & וצ' & $101, Y 7$ & مقياس تقدير \\
\hline
\end{tabular}

\& من الجدول السابق لحساب الفروق بين متوسط درجات عينة الدراسة (الزوار والسكان) لأبعاد مقياس تقدير الثخصية يتضح وجود فروق ذات دلالة إحصائية بين منوسط درجات

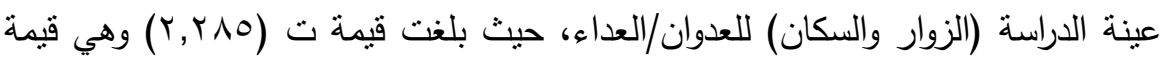

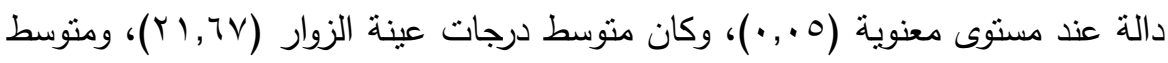

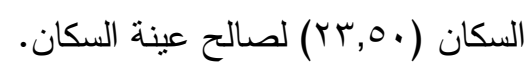

ك بينما لم يكن هناك فروق ذات دلالة إحصائية بين متوسط درجات عينة الدراسة (الزوار

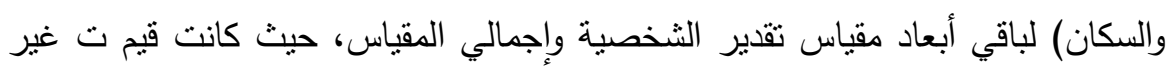

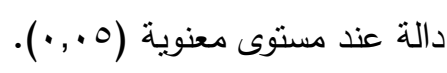

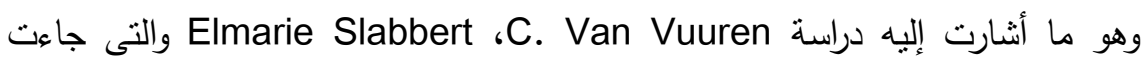
تحت عنوان: دوافع السفر وسلوك السياح فى منتجع جنوب افريقيا، وهدفت الدراسة إلى دالى التعرف على دوافع سفر السياح إلى منتجع جنوب افريقيا ومدى ارتباط تلك الدوافع بسلوك السائحين، وعرفت الدراسة سلوك السائح بأنه تفاعل بين شخصية الباحث دون والمتغيرات البيائية

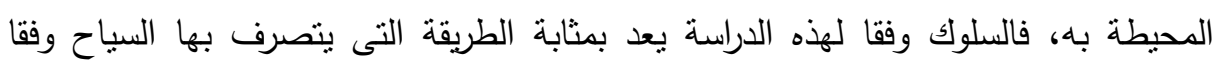

$$
\text { لمواقفهم تجاه منتج معين. }
$$


وأجريت الدراسة على عينة قوامها ـ10 مفرده من السياح المترددين على منتجع جنوب افريقيا، واعتمدت الدراسة على المنهج الوصفى التحليلي وعلى نموذج " ماسلو لتحديد الاحتياجات الاجتماعية، كما توصلت الدراسة إلى مجموعة من النتائج أهمها:

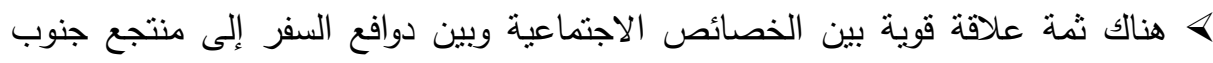
افريقيا. \& وصف الدراسة سلوك السائحين فى منتجع جنوب افريقيا بالسلوك الحضاري. ه نوصلت الدراسة إلى أن معرفة سلوك السائحين ودوافع سفرهم يسهم بدور كبير فى الترويج السياحى والتخطيط للأنشطة السياحية. جدول(ץ): اختبار ت T-Test لحساب الفروق بين متوسط درجات عينة الدراسة (الموظفون والسكان) لأبعاد مقياس تقدير الثخصية

\begin{tabular}{|c|c|c|c|c|c|c|}
\hline \multirow{2}{*}{ الالالة عند معند } & \multirow[b]{2}{*}{ قَيمة } & \multicolumn{2}{|c|}{ الزوار (ن= = } & \multicolumn{2}{|c|}{ الموظفون (ن= ·r) } & \multirow[b]{2}{*}{ المتغيرات } \\
\hline & & الالاتحراف & المتوسط & الالانحراف & المتوسط & \\
\hline غير دالة & • & $r, \cdot \varepsilon$ & $r r, 19$ & 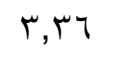 & rr, & النظرة السلبية للحياة \\
\hline دالة ل & $r, \wedge$. & $r, 09$ & 19,90 & $\overline{Y, Y V}$ & $r r_{,} \cdot V$ & عدم الثبات الإنفعالي \\
\hline غير دالة & $1, r 1$. & r, & $r, r$. & $r, \cdots$ & YY,r. & عدم التجاوب مع الآخرين \\
\hline غير دالة & $\cdot, 7 / \wedge$ & $\Lambda, 01$ & $\sum 1, \Sigma Y$ & $\Gamma, \varepsilon \Gamma$ & $\varepsilon r, \varepsilon r$ & تقويم الذات \\
\hline غير دالة & $\cdot, 19$ & $r, r_{q}$ & $r \cdot, Y T$ & $r, 91$ & $r \cdot, \Sigma \cdot$ & أ- عدم الكفاءةالشخصية \\
\hline غير دالة & $\cdot, V Y Y$ & $7,1 \mathrm{~V}$ & $Y 1,17$ & Y,Vq & YY,.r & ب- التقدير السلبي للذات \\
\hline دالة & $r, q Y \varepsilon$ & $r, r_{q}$ & $Y r, V T$ & Y,74 & YY,OV & الإعتمادية \\
\hline دالة & 0,110 & $\varepsilon, \Gamma$ & YI,TV & $r, 11$ & Y૫, ¿r & العدوان/العداء \\
\hline دالة د مالة & Ar. & $17, Y 7$ & 17 & 7 & iv & إجمالى مقياس تقدير \\
\hline
\end{tabular}


من الجدول السابق لحساب الفروق بين متوسط درجات عينة الدراسة (الموظقون والزوار) لأبعاد مقياس تقدير الشخصية يتضح الآتي:

ه وجود فروق ذات دلالة إحصائية بين منوسط درجات عينة الدراسة (الموظفون والزوار)

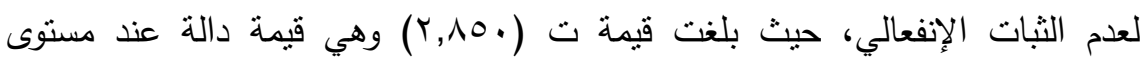

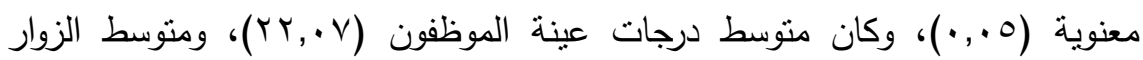

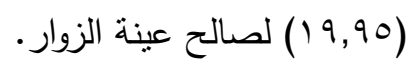

ه وجود فروق ذات دلالة إحصائية بين منوسط درجات عينة الدراسة (الموظفون والزوار)

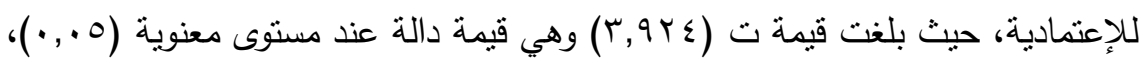

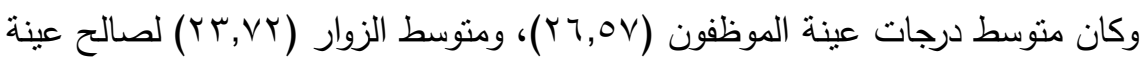

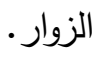
ه وجود فروق ذات دلالة إحصائية بين منوسط درجات عينة الدراسة (الموظفون والزوار)

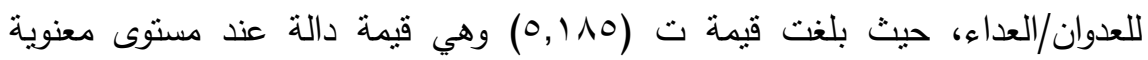

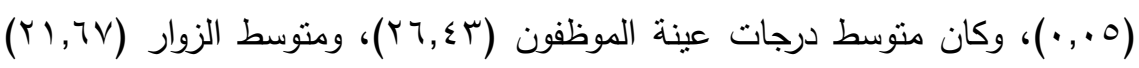
لصالح عينة الزوار. وجود فروق ذات دلالة إحصائية بين منوسط درجات عينة الدراسة (الموظفون والزوار)

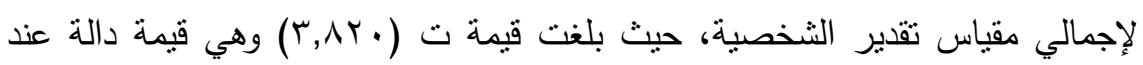

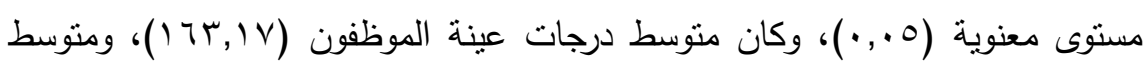

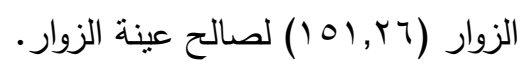

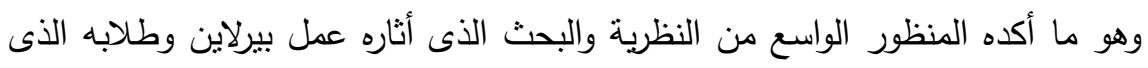
يتعامل مع وظيفة خصائص معينة من المثير عند إثارة الانتباه منها حب الاستطلاع والثيل والميل والسلوك الاستكثافى والاختيار المفضل وغيرها تعامل عمل هؤلاء مع دور خصائص المثيرات

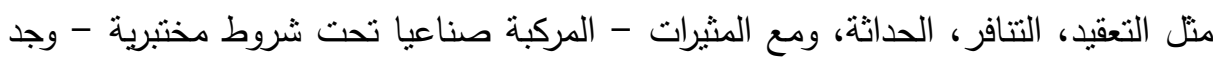
تطبيق على ميادين متنوعة من ضمنها الاستجابة للفن، الموسيقى، سلوك اللعب وغير ذللك.

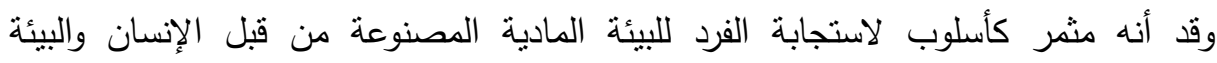


الطبيعية ويشكل أساسا لميدان فرعى منطور من علم النفس البيئي الذى يمكن أن بصمم كميدان لعلم الجمال البيئي. كما أن هناك أسلوب مختلف جدا فى النظر إلى علاقات البيئة - السلوك هو التركيز على المحيط المكانى للسلوك - حيث يكمن وراء الحقيقة البديهية أن السلوك محدد بالمجال

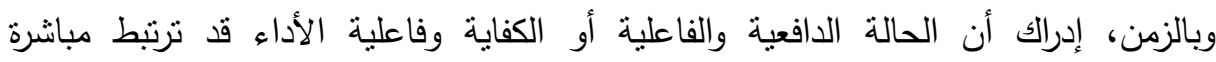

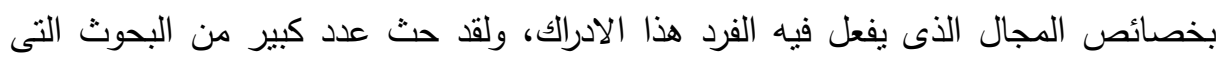

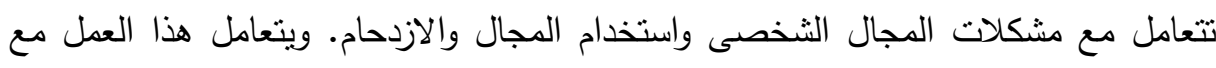

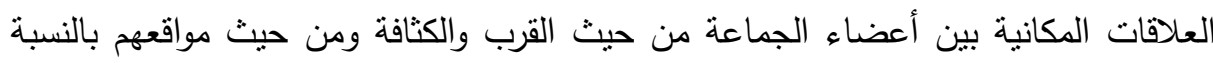
للفرد. يمكن التعامل مع البيئة على أنها تمنل موقع أو محيط للسلوك بمعنى علم البيئة وهو

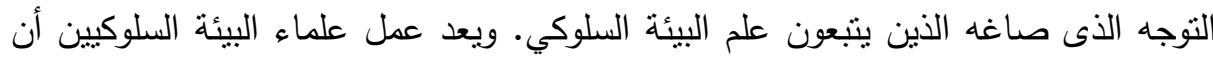

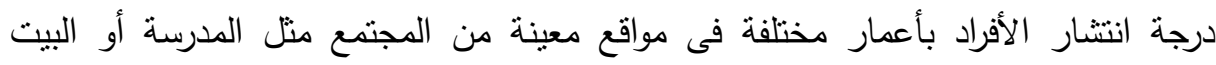
وغيرها، وكذلك درجة وطريقة مشاركة الفرد فى الفعاليات - المعرفة فى محيط سلوك معين أثنار هذا التوجه. 
أحمد مصطفى العتيق وآخرون

جدول(؛ ): قيمة الارتباط بين مقياس الاستبيان ومقياس تقدير الثخصية لعينة السكان

\begin{tabular}{|c|c|c|c|c|c|c|c|c|c|c|}
\hline 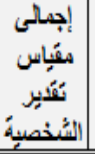 & العذون/الغذاه & |الإعتمادية | & |السنبّير & أ- ألعثادة & 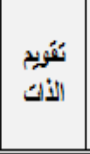 & |الَّجاوبي & 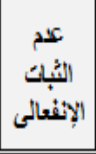 & لالمباةً & & (1) \\
\hline${ }^{*} \cdot\{\pi T$ & & YT- & $\because,+\{Y-$ & $" \because, Y 07$ & $\begin{array}{l}0,491 \\
\end{array}$ &., 111 & ${ }^{\prime \prime},, 01 \%$ & 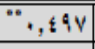 & & \multirow{2}{*}{ 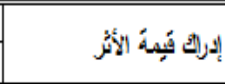 } \\
\hline$\theta, \cdots$ & &,$+ \lambda$ & $\cdot, 7$ &,$\cdots$ & \begin{tabular}{|l|}
,,$\cdots$ \\
\end{tabular} &,,$+r$ &,$+ \cdots$ & , , , & الالاد & \\
\hline$" \cdot, r v v$ & או & 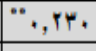 & $=\cdot, r .$. & $" \cdot$, or. & $., 1, V$ & $\because, \Gamma Y Y$ & $\because, \varepsilon \cdot \varepsilon$ & $", r+r 9$ & كعامل & \multirow{2}{*}{ 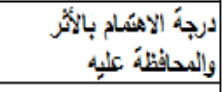 } \\
\hline,$++r$ &,$\ldots$ &,,,$\ldots 1$ & $\because, \cdots 1$ &,$\cdots$ &., 1 & $\cdot, \cdots$ &,$\cdots$ &,$\cdots$ & الدال| & \\
\hline., 19 & & 71 & $\because, \because,-$ & $., 1, r-$ &,$++1 \leqslant-$ & $\because, 10 \leqslant-$ & , & $0,, 01$ & معامل & \multirow{2}{*}{ 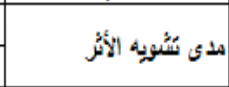 } \\
\hline.,$v$ & 10 & $r 49$ & $\because, 0, N \mathrm{Y}$ &., 101 &,$\lambda$ &,,+4 &, 0 &,, \& & إلالأة & \\
\hline$\because, Y Y O_{0}$ & rTY & 170 & $\cdots, Y \leqslant 9]$ & $\because, r \cap Y$ & $\because \theta, r T \leqslant$ & $\because, 10$. & $\because, r v$. & $\because, r+1$ & معامل الازبتَبة & \multirow{2}{*}{ 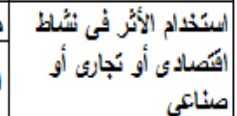 } \\
\hline & & & & & & $\cdot,+\&$ &,$\cdots$ &. .1 & |الدلالة & \\
\hline .077 & 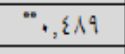 & TYY & $=\cdot, \varepsilon+\gamma$ & $\because, r \vee 9$ &, 470 &,$+ \cdots \Lambda^{-}$ &,$\leqslant 71$ & ${ }^{*} \cdot, \xi$ & معامل & \multirow{2}{*}{ 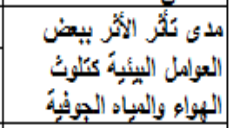 } \\
\hline & & & & & & $\cdot, 9$ & &,$+ \cdots$ & & \\
\hline$\because, Y, M V$ & דודז," & $0,11$. & $=0, \Gamma \leqslant 0$ & $*, \varepsilon, \varepsilon$ & $\because, Y, Y T$ & $0,1 Y T$ &,,$+ N Y$ &,$++Y 1$ & معامل الارنبَّط & \multirow{2}{*}{ الائسام بالحى ككل } \\
\hline $9, \cdots 1$ & 1. & $\theta, 1$ & $\cdot, \cdots$ & $\therefore, \cdots$ &,$\cdots$ &, 7 &,$r$ & $\cdot, \Lambda$ & الدעل & \\
\hline$" \cdot, \varepsilon r V$ & $" \cdot, \varepsilon \varepsilon Y$ & $\because, r>\varepsilon$ & $\because, r Y$, & $\because, Y 9 \wedge$ & $\because, r i r$ &., $10_{0-}$ & $\because, r \leqslant v$ & $\because, r v \leqslant$ & معامل الازئباط & \multirow{2}{*}{ 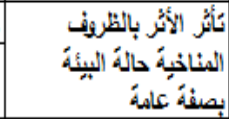 } \\
\hline & & & &,$\cdots$ &,,,$+ r$ & $\cdot,+\wedge$ &,,$\cdots$ & ( & 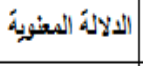 & \\
\hline$", r Y A$ & $" \cdot, r T V$ & $17 r$ & $\because, y, 1$ & $" \cdot, r, Y$ & $\begin{array}{r}*, 199 \\
\end{array}$ & $\because, 1 \leqslant \mathrm{~V}-$ & 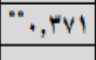 & $\because, r y \mathrm{rV}$ & لارنبً & \multirow{2}{*}{ 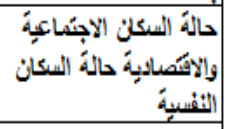 } \\
\hline,$\cdots$ & & &,$\cdots$ & 1 & 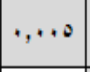 & $\cdot,+\&$ & 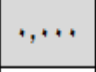 &,$+ \cdots 1$ & لـة المغنوية & \\
\hline$\therefore, 1 / 1$ & 1,027 & $", r Y_{0}$ & $\because, 0$, & $" \cdot, r \wedge \varepsilon$ &,,$+r$ &., $19 \Lambda-$ & , & 9 & معامل الازبَبطاط & \multirow{2}{*}{ عوامل الجب للسباح } \\
\hline,+4 &,$\cdots$ &,$\cdots$ & $\because, \cdots$ & $\therefore, \cdots$ &,$\wedge$ &,,$\cdots 0$ &,,+1 &,$+ r$ & الالالة المغنوية & \\
\hline$, 1,1 Y$ & ivy & 1.5 & $\cdot,+Y Y$ & $0,1 Y 1$ &, $1 \vee \varepsilon$ &., 10 & $\therefore, r+1$ & 111 & معامل الارَبَّط & \multirow{2}{*}{ عوامل الطرد اللسبياح } \\
\hline$\cdot, 1$ & 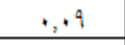 & $\theta 0$ &,,$\Lambda$ & $\cdot, Y$ &,,+1 &,+ 1 & $\cdot, 4$ &,$r$ & الالالةً المغنوية & \\
\hline $0,1 \%$. & 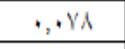 & $0,11 Y$ & $=0, \pi r$ & $\because,\{07$ & $\cdot, 1+V$ & ${ }^{*},, Y 9 \varepsilon$ & $\because, r 91$ & $" \cdot, \varepsilon+1$ & معامل الارَبَّاط & \multirow{2}{*}{ علايَة السكان بالسباح } \\
\hline, 7 & $x_{1}$ &,$r$ &,,$\cdots$ &,$\cdots$ & $\cdot, 1$ & $\therefore$ & $\therefore, \cdots$ &,$\cdots$ & الالالة المغنوية & \\
\hline$\because, r \gamma_{0}$ & $\because, 0,1$ & $\because, Y, 10$ & $-0,077$ & $\because .010$ & $\theta, \cdot V$ & $\because, \mathrm{rON}-$ & $\because$, ros & $\because, 10$. & معامل الارتبَّط & \multirow{2}{*}{ |إجملى الآسنيّين } \\
\hline,$\ldots$ &,$\ldots$ &,$\ldots$ & $\cdot, \ldots$ & 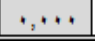 & , &,,$\ldots$ & , , , &,,$+\notin$ & |الالالة المغنوية & \\
\hline
\end{tabular}

من الجدول السابق يوضح قيمة الارتباط بين أبعاد الاستبيان ومقياس تقدير الثخصية

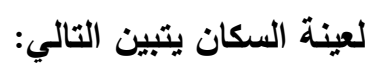

> نوجد علاقة ارتباطية ذات دلاله إحصائية عند مستوى معنوية (0., •) بين إدراك قيمة الأثر وكل من (النظرة السلبية للحياة - عدم الثبات الإنفعالي - عدم التجاوب مع الآخرين

- تقويم الذات - عدم الكفاءة الثخصية - إجمالي مقياس تقدير الثخصية) لعينة السكان

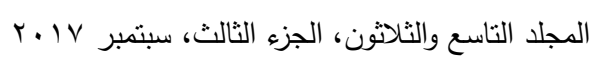




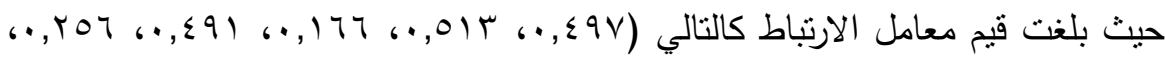
r ه توجد علاقة ارتباطية ذات دلاله إحصائية عند مسنوى معنوية (ه.,.) بين درجة

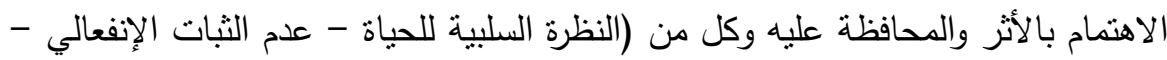
عدم التجاوب مع الآخرين - عدم الكفاءة الثخصية - التقدير السلبي للذات - الإعنمادية - العدوان/العداء - إجمالي مقياس تقدير الثخصية) لعينة السكان حيث بلغت قيم معامل

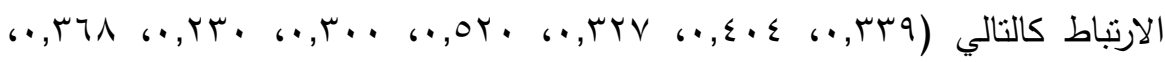
$\cdot(\cdot, r \vee V$ > توجد علاقة ارتباطية عكسية ذات دلاله احصائية عند مستوى معنوية (0., •) بين مدى الحى تشويه الأثر و (عدم التجاوب مع الآخرين) لعينة السكان حيث بلغت قيمة معامل الارتباط $\cdot(\cdot, 10 \leqslant-)$ ك توجد علاقة ارتباطية ذات دلاله احصائية عند مستوى معنوية (0. . •) بين استخدام الأثر في نشاط اقتصادي أو تجاري أو صناعي وكل من (النظرة السلبية للحياة - عدم الثبات الإنفعالي - عدم التجاوب مع الآخرين - تقويم الذات - عدم الكفاءة الثخصية - التقدير السلبي للذات - الإعتمادية - العدوان/العداء - إجمالي مقياس تقدير الثخصية) لعينة

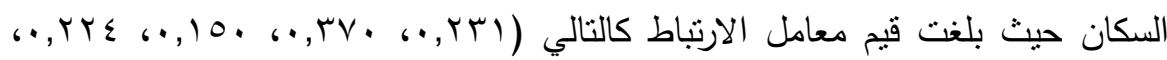

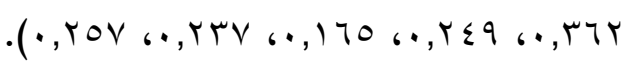
> نوجد علاقة ارتباطية ذات دلاله احصائية عند مستوى معنوية (0., •) بين مدى تأثز

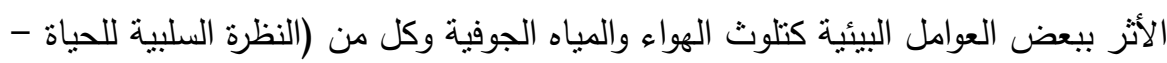
عدم الثبات الإنفعالي - تقويم الذات - عدم الكفاءة الثخصية - التقدير السلبي للذات الإعتمادية - العدوان/العداء - إجمالي مقياس تقدير الثخصية) لعينة السكان حيث بلغت

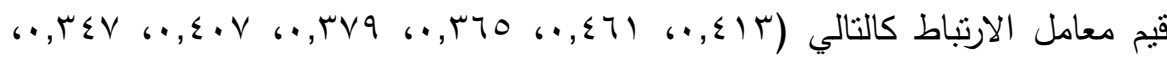


ك نوجد علاقة ارتباطية ذات دلاله إحصائية عند مستوى معنوية (0. . •) بين الاهتمام بالحي ككل وكل من (تقويم الذات - عدم الكفاءة الشخصية - التقدير السلبي للذات العدوان/العداء - إجمالي مقياس تقدير الثخصية) لعينة السكان حيث بلغت قيم معامل

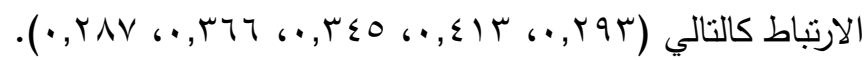

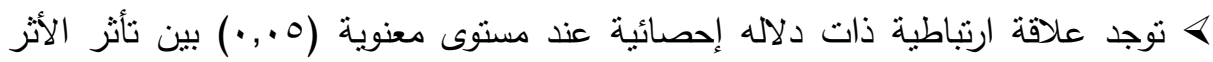

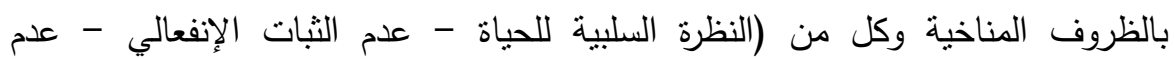
التجاوب مع الآخرين - ثقويم الذات - عدم الكفاءة الثخصية - التقدير السلبي للذات الإعتمادية - العدوان/العداء - إجمالي مقياس تقدير الثخصية) لعينة السكان حيث بلغت قيم معامل الارتباط كالتالي (

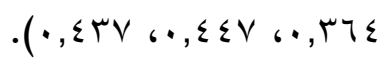

ك توجد علاقة ارتباطية ذات دلاله إحصائية عند مستوى معنوية (0. . • ) بين حالة السكان

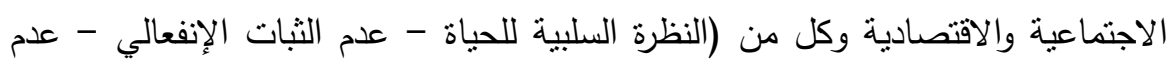

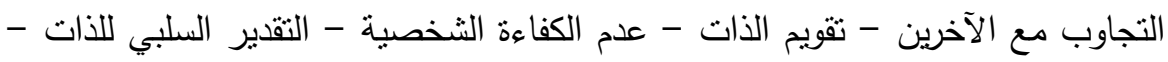
الإعتمادية - العدوان/العداء - إجمالي مقياس تقدير الثخصية) لعينة السكان حيث بلغت

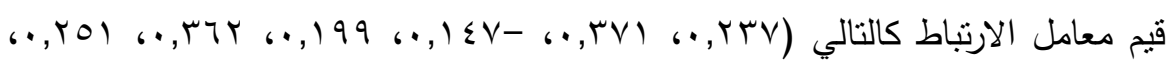
( TVA نوجد علاقة ارتباطية ذات دلاله إحصائية عند مستوى معنوية (0., •) بين عوامل الجذب للسياح وكل من (عدم التجاوب مع الآخرين - عدم الكفاءة الثخصية - التقدير السلبي

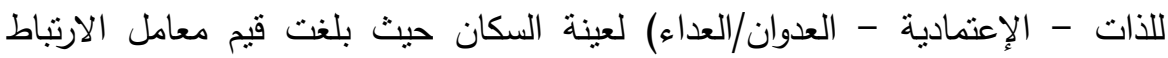

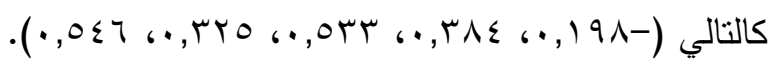

ك توجد علاقة ارتباطية ذات دلاله إحصائية عند مسنوى معنوية (0. . •) بين علاقة السكان بالسياح وكل من (النظرة السلبية للحياة - عدم الثبات الإنفعالي - عدم التجاوب مع دله

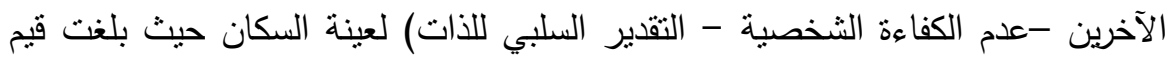

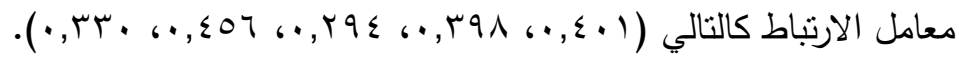


ك نوجد علاقة ارتباطية ذات دلاله إحصائية عند مستوى معنوية (0.,•) بين إجمالي

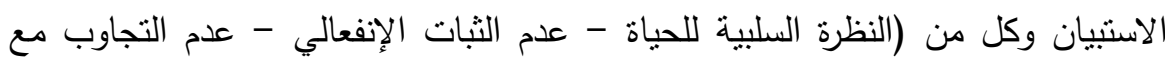

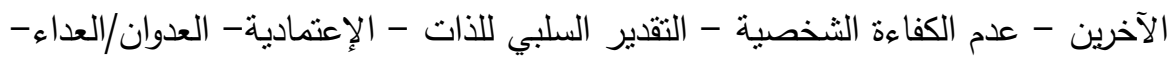
إجمالي مقياس تقدير الثخصية) لعينة السكان حيث بلغت قيم معامل الارتباط كالتالي

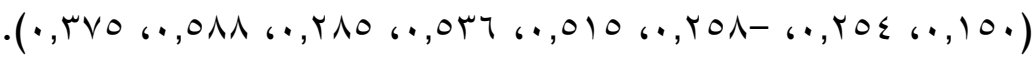
ه بينما لا نوجد علاقة ارتباطية ذات دلاله إحصائية عند مستوى معنوية (ه ., •) بين باقي أبعاد الاستبيان ومقياس تقدير الثخصية.

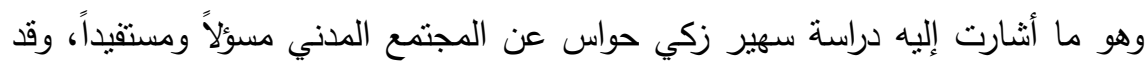
جاءت هذه الدراسة في الباب الثاني من كتاب "الحفاظ العمراني وإحياء المناطق التراثية في مصر"تطبيقاً على مشروع مؤسسة أغاخان بالدرب الأحمر. ترى هذه الدراسة أن إنجاح

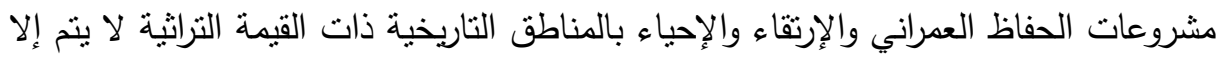
بمدى إستيعاب المجتمع المدني والمحلي بأهمية تلك المشروعات وأن يكون لايهم قناعة

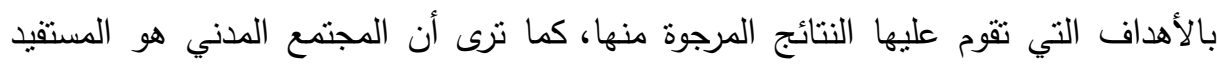

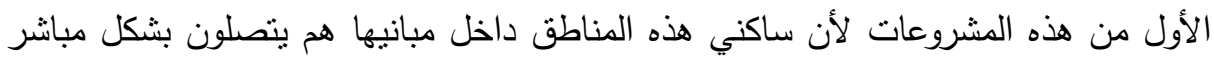

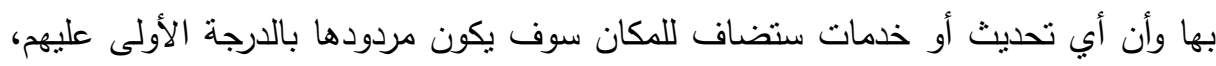

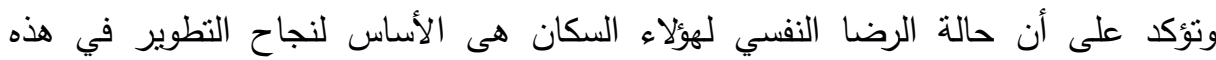

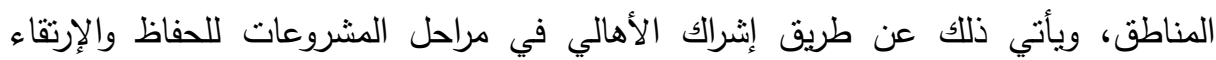
بالمنطقة، ومن هنا تتحقق الإستدامة للمشروع وللمنطقة التراثية. كذلك عندما يتم إنجاز هذا المشروع والحفاظ العمراني على المكان يكون المجتمع المدني هو الداعم الحقيقي لحماية ما تم من أعمال كما أنه يحرص على صيانته واستثامته، وبذلك يكون الحفاظ والإرتقاء بالمناطق

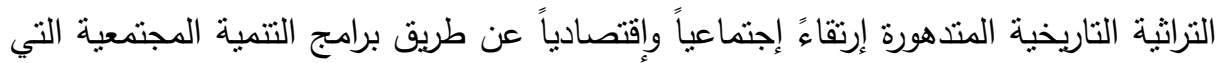

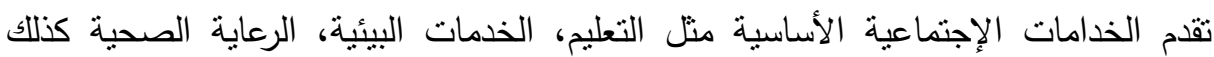
النظافة ورفع القمامة وجمعها، وإعادة تأهيل المباني السكنية المتدهورة تشجيع الأهالي على الألى 
أحمد مصطفى العتيق وآخرون

الإهتمام بتتمية مجتمعهم كإعطائهم قروض بسيطة ميسرة تكون حافز لهم من أجل تحسين

وتتمية مجتمعهم.

جدول(ه): قيمة الارتباط بين أبعاد الاستبيان ومقياس تقدير الشخصية لعينة الموظفين

\begin{tabular}{|c|c|c|c|c|c|c|c|c|c|c|}
\hline 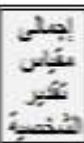 & 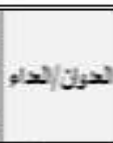 & [खा? & $\frac{5}{20}$ & 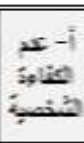 & $\frac{2 \pi}{03}$ & 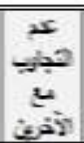 & $\mid \frac{25}{203}$ & $\frac{1}{20}$ & \multicolumn{2}{|r|}{ ستري } \\
\hline$\because, r: A$ & $=0, t 2 \pi$ & $-, T, 4$ & $\therefore, \ldots$, &,++7 &,,-++54 & $\because, 5,49$ &,$-+* T$ &.,+ 214 & 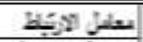 & \\
\hline$\ldots, \ldots \gamma$ &,$- \ldots$ & $\therefore,-4$ & 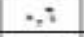 &,- 7 &,$- \ldots$ &,$- \ldots$ &,- 2 & $\sim, \ldots$ & 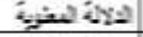 & \\
\hline 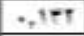 & $\cdot, \cdot A Y$ & $-\pi \mathrm{sh}$ &.,$\ldots$ AV &., $.1 \pi$ & דוז. & 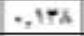 &,$\ldots+1$ & 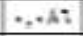 & 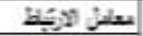 & \\
\hline$\cdot, T$ & 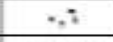 & $0, .9$ &,+ 7 & $\cdot, 5$ & $\cdot, \AA$ & $\cdot, \mathrm{f}$ & $\cdot, v$ & $\cdot, 7$ & 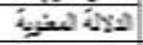 & \\
\hline - & , & $\cdot, \cdot T_{i}$ & $\ldots \pi$ &,$+ \ldots$ A: & $-, 1,4 \pi$ &.,$\pi 0^{2}$ &,$+ 1+x$ & $*, \cdots \mathrm{Y}$ & بالر & \\
\hline$+\pi$ &,$+ k$ & $+x^{4}$ &., 45 &,$+ \pi$ &,$+ \pi$ &,$- T$ &,$+ \varepsilon$ & $1, \cdot$ & 4042 & \\
\hline$\cdot, 11 \cdot-$ &,$++v-$ &,$- 19 y$ & $\theta, r+1$ & $\cdot, \mathrm{T} \cdot$ & $*, * 1$ & $\cdot, * * 2$ &,$- 19 x-$ & 0,174 & سطال فيكية & \\
\hline$+\pi$ & $+\pi$ &,-+7 & $\ldots,+1$ &,$+ * 7$ &,+ 7 & $\cdot, 2$ & $\therefore, \cdots$ & $\cdot \pi$ & $4 y^{2} 4 x$ & - \\
\hline., $1+2$ & $\theta, T \cdot t$ & 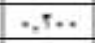 &., $\mathrm{AST}$ & -190 &., 141 & $\cdot, T \cdot A$ & 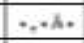 & $\ldots 1$ & 4 & \\
\hline$\cdot \pi$ &.,$\cdot 3$ &,++7 & $*, * \psi$ &,+-3 & 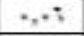 &,,-+ 4 &,+ 3 &,- 7 & 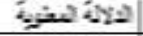 & \\
\hline 4 & $\theta, T \leq$ & 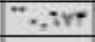 & 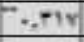 & .789 & .,7tr & $-\cdot, 7+1$ & $*+\pi$ &., 74 & س & \\
\hline$\cdot,-1$ &.,$\pi$ &,$- \ldots$ & $\ldots, \ldots 1$ & $\ldots \ldots$ & $\cdot \ldots$ &.,$\cdots$ & $\cdot \hat{A}$ & $\cdots, \ldots$ & 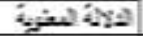 & \\
\hline $0, \cdot 1 \pi-$ &.,$+\pi$ & $=-2,24$ & {$[-, 774$} & {$[\cdot, 7, \pi$} & $\because, 2 \leq$. & {$[-, t 20]$} &,$- \ldots+4-$ & {$[-, 074$} & سيل دربية & \\
\hline$\cdot, 5$ & 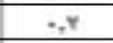 & $*, \ldots$ & $\ldots, \ldots \gamma$ & $\cdot \ldots$ &,$+ \ldots$ & $\cdot, \cdots$ & $\sigma_{,} \Psi$ & $*, \ldots$ & 40201 & \\
\hline$\cdot,+19$ &., $1+1$ & -, & $\cdot, 1$, &,$+ \mathrm{ri}$ &,$+ 1+1$ &,$- \pi * r$ & $n+4$ &., $1 \pi$ & 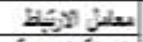 & \\
\hline$\cdot, A$ & $\theta, 5$ & $\cdot, \cdot A$ &., 1 &,$- 0^{4}$ & $*, 2$ &., .4 & $\cdot, A$ & $-\pi$ & 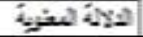 & \\
\hline,$\cdots+1-$ &,$+ * \leqslant \gamma-$ & 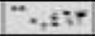 & זיו, & $=., 27$ & $" \cdot \cdot, \pm \pm A$ & {$[-,+\Delta T$} & $\cdot,+* n$ & 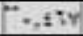 & سعلر ائبة & 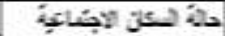 \\
\hline$\theta, \mathrm{Y}$ & 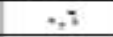 &,$- \ldots$ & $-\pi$ & $\cdot \ldots$ &,$+ \cdots$ &,$\ldots$ & $.2 \%$ &,$+ \cdots$ & 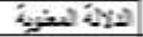 & \\
\hline זי, & $\cdot, 1 \pi$ & 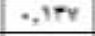 & -,$\pi \lambda Y$ & $\cdot, \mathrm{Try}$ & .,178 &., $19 \gamma$ &,- 114 & $\cdot, 11,4$ & سعلر المئيد & \\
\hline 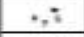 &,+ 8 &,$+ \varepsilon$ &,$+ \cdot \%$ & $*,+A$ &,$+ \pi$ & $\cdot, \pi$ & $=, \pi$ &,$+ *$ & 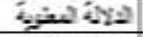 & \\
\hline, $1 \mathrm{rw}-$ &,$- 114-$ & $\because, 27$ & .,172 & $\because, 0, \mu$ & 0,732 & \begin{tabular}{|l|l|} 
\\
\end{tabular} &., $1 \cdot \pi-$ & $x, \pi T$ & معرد فيكبة & \\
\hline$*, * 4$ & $\cdot \pi+4$ & $\cdot, \cdots$ &., 1.9 & $\cdot \ldots$ &,$\cdots$ &,+ & $+\pi$ &.,.,$T$ & 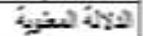 & \\
\hline$\cdot, \cdots$ &,$+ \ldots$ &.,+24 & $\cdot, \cdot \pi$ & $\cdot,+*$ & $-\cdot-, 4 \div 4$ &,$+ \cdot \mathrm{vr}$ &,$-+7^{4}$ &,$- 1+1$ & ta & \\
\hline., 7 &,- 7 & $\theta_{n} 7$ &., 5 & $\cdot, \gamma$ & $\ldots, \ldots$ & $\cdot, 2$ & $\cdot, A$ &.,$T$ & 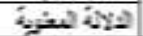 & \\
\hline,$- \pi \cdot z$ &.$\pi 1$ & $\cdot, 14$. & - &., 159 & $=,-721$ &,$- \pi+1$ &,,$-+25-$ &., $1 \pi$ & سعرل الديبلي & \\
\hline$*,+3$ & .1 & 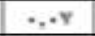 &,++3 & $*, * 7$ &,$+ \ldots$ & 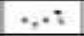 &,$+ v$ &., 5 & 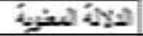 & \\
\hline$=,+\pi 19-$ & -, & $\cdot \cdot, v+\varepsilon$ & $\because, \pi, \psi$ & $\because, \mathrm{val}$ & $-\cdot, v, v$ & $\theta,+\pi, T$ &., $192-$ & $\cdot \cdot, 2 \mathrm{AT}$ & مبلز الوربيا & \\
\hline$\ldots \pi$ & $\because, \ldots A$ &.,$\ldots$ & $2,+t$ & $\therefore \ldots$ &,$\ldots$ & $\cdot, \ldots$ & $\cdot, \cdot 2$ &,$\ldots$ & (1) & \\
\hline
\end{tabular}

من الجدول السابق يوضح قيمة الارتباط بين أبعاد الاستبيان ومقياس تقدير الثخصية

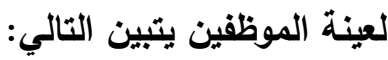

ه توجد علاقة ارتباطية ذات دلاله إحصائية عند مستوى معنوية (0., •) بين إدراك قيمة

الأثر وكل من (النظرة السلبية للحياة - عدم التجاوب مع الآخرين - تقويم الذات -

الإعتمادية - العدوان/العداء - إجمالي مقياس تقدير الثخصية) لعينة الموظفين حيث

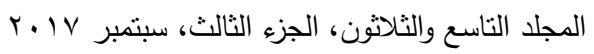




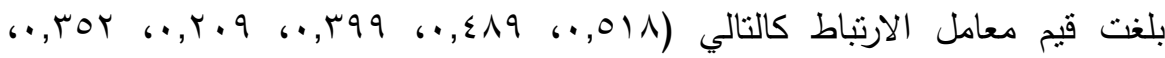

> توجد علاقة ارتباطية ذات دلاله احصائية عند مستوى معنوية (0. , •) بين استخدام الأثر في نشاط اقتصادي أو تجاري أو صناعي وكل من (التقدير السلبي للذات) لعينة الموظفين

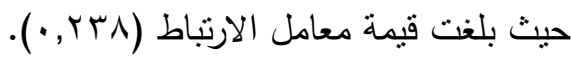

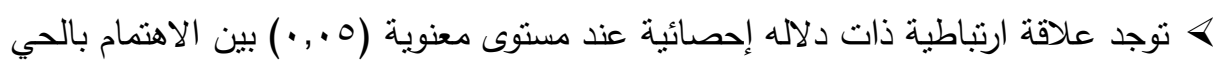
ككل وكل من (النظرة السلبية للحياة - عدم التجاوب مع الآخرين - تقويم الذات - عدم

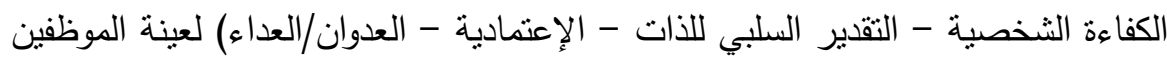

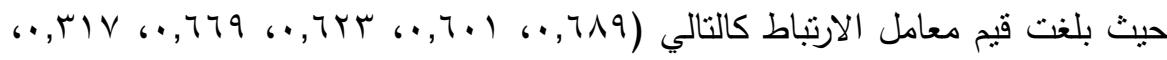

$$
\cdot(\cdot, Y \leq \cdot 6 \cdot, T V T
$$

> نوجد علاقة ارتباطية ذات دلاله إحصائية عند مستوى معنوية (0., •) بين تأثز الأثر بالظروف المناخية وكل من (النظرة السلبية للحياة - عدم التجاوب مع الآخرين - ثقويم الذات - عدم الكفاءة الثخصية - التقدير السلبي للذات - الإعتمادية) لعينة الموظفين

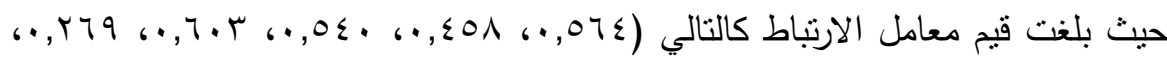
.$(\cdot, 09$.

ه نوجد علاقة ارتباطية ذات دلاله إحصائية عند مستوى معنوية (0., •) بين حالة السكان الاجتماعية والاقتصادية وكل من (النظرة السلبية للحياة - عدم التجاوب مع الآخرين -

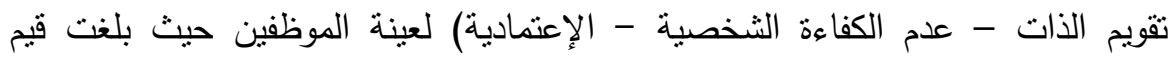

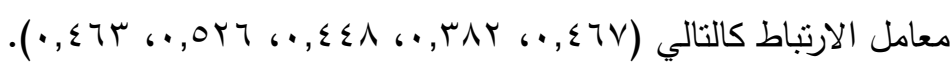

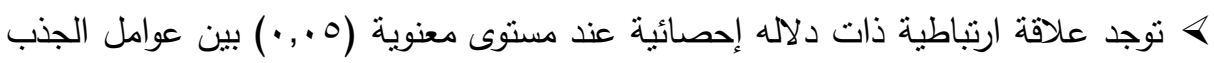
للسياح وكل من (النظرة السلبية للحياة - تقويم الذات - عدم الكفاءة الثخصية -

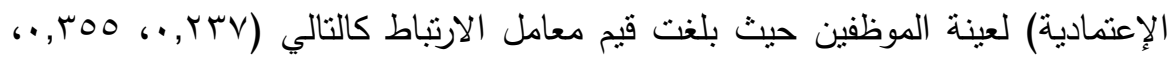


ك نوجد علاقة ارتباطية ذات دلاله احصائية عند مستوى معنوية (0., •) بين عوامل الطرد

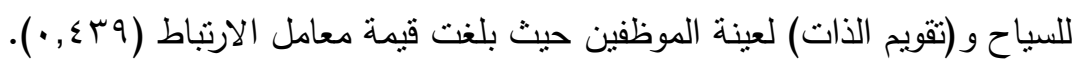
ه نوجد علاقة ارتباطية ذات دلاله إحصائية عند مستوى معنوية (0.,.) بين إجمالي

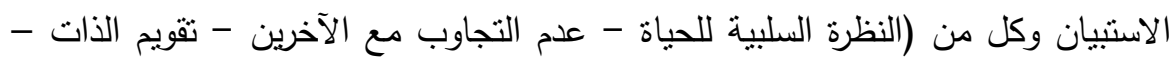
عدم الكفاءة الثخصية - التقدير السلبي للذات - الإعنمادية) لعينة الموظفين حيث بلغت التهبن

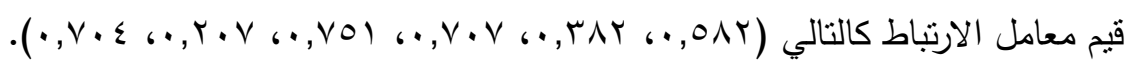
ه بينما لا توجد علاقة ارتباطية ذات دلاله إحصائية عند مستوى معنوية (ه . . •) بين باقي أبعاد الاستبيان ومقياس تقدير الثخصية. اتفقت النتائج مع دراسة باهر اسماعيل حلمى فرحات، بعنوان "العلاقة التبادلية بين

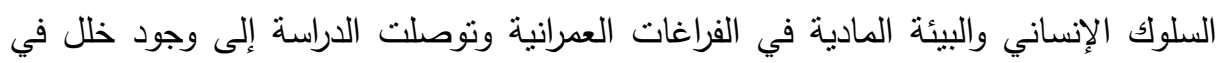
العلاقة التبادلية بين السلوك الإنساني والبيئة المادية في منطقة ميدان الأوبرا وحديقة الأزبكية

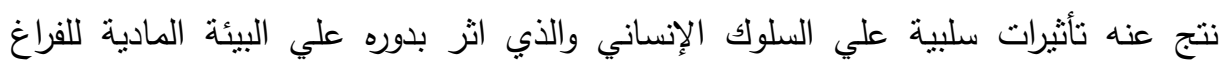
العمراني. وخلصت الدراسة إلى أن العلاقة بين الفراغات العمرانية وبين السلوكيات الإنسانية علاقة تبادلية ووجود أي قصور في الدراسات الإنسانية (السلوك الإنساني) يعوق من تأدية الفراغات العمرانية (البيئة المادية) لوظائفها الاقتصادية والاجتماعية والترفيهية والثقافية. 
جدول(7): قيمة الارتباط بين مقياس الاستبيان ومقياس تقدير الثخصية لعينة الزوار

\begin{tabular}{|c|c|c|c|c|c|c|c|c|c|c|}
\hline 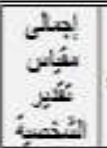 & | & إعلشلية & =- & أ- كند & نان & مجنّ & 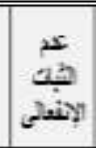 & $\frac{5100}{3011}$ & \multicolumn{2}{|r|}{ الشيخرت } \\
\hline $8+\ldots+1-$ &,$+ \cdot+7$ & $8,1+4$ & $8,+24-$ &,$+ 1 \pi .-$ & (1) &.,$+2 \mathrm{~A}^{-}$ & $\because *, r+4$ & $\cdots$, th. & 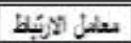 & \multirow{2}{*}{ 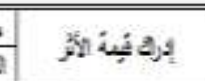 } \\
\hline,$+ y$ &,$- 30 \%$ & $\cdot, \cdot 2$ &,+ 7 &.,$\pi$ &,+ 4 &,$;$ &,$\ldots 1$ & $\ldots+\cdots$ & 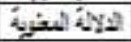 & \\
\hline.,$I v y$ & 4,174 & $\therefore, 1+4$ & 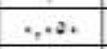 & $\therefore, 1, A Y$ & . &,$- v V y$ & 4,174 &.,+79 & 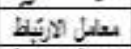 & \multirow{2}{*}{ 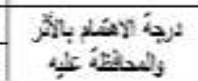 } \\
\hline,$+ \cdot 4$ &,$+ T$ & $\cdot \pi$ &,$+ i$ & +1 &,+ 4 & 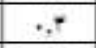 & $+\pi$ &.,$A$ & 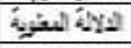 & \\
\hline$\cdot,++1$ & 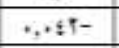 & . &.,$\pi 1$ & ., &., $19 \gamma$ &,- 145 & $\cdot, \cdot f t$ &.$+*$ & سبلر لهئبط & \multirow{2}{*}{ 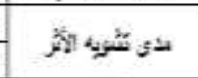 } \\
\hline$\cdot, \cdot i$ &,$+ y$ & $\cdot,+r$ &,++1 &.,$+r$ & 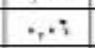 &,$+ \cdot i$ & $\cdot, i$ & $\cdot, y$ & (1) & \\
\hline$\theta,+1+\lambda-$ &,$+ \pi$ &,+ 114 & $\cdot \because, r+y-$ &,$+ \cdots A-$ & $\cdot, 17,-$ & $\cdots,+,+4$ & $\cdot, 1+h-$ &., $1+1-$ & بعل اينبة & \multirow{2}{*}{ 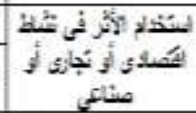 } \\
\hline , & +.0 .6 &,+ 1 &,$++\pi$ & $\cdot, 4$ & +9 & 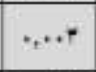 & ז', & 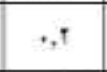 & لالية السفية & \\
\hline 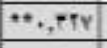 & $*+, 17$ & $\therefore \cdots 2$ & $*_{+,+}+2 t$ & 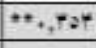 & 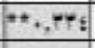 & ., &., $1 \% A$ & -, & سبل لوزئبة & \multirow{2}{*}{ مثرئ } \\
\hline,$\cdots 1$ &,$\ldots$ & $\cdot, 4$ & .. &,$+ \cdots$ &,,$\cdots$ & $\cdot T$ & $\theta$ & $\cdot, A$ & الالائ الفئية & \\
\hline,$+ \pi$ &,$++74-$ &., $15 \%$ & . IAt & $\theta,(x)$ &., $1 \%$ &., $11 \cdot-$ & 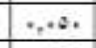 &,$+ T A Y$ & سعلد لوزئبة & \multirow{2}{*}{ لانسان بلدى ك5ال } \\
\hline$\cdot, k \leqslant \uparrow$ &,+ 8 &,++ & $\cdot+1$ &,$\pi$ & $+\pi$ &.,+ & $r i$ & 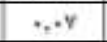 & (لفئ & \\
\hline,$+ 111-$ & - &., $1+v$ &., $1 \pi$ & $\cdot, 1 \mathrm{~A}$ & $\theta, 17 s$ &., $17 \pi-$ &., 51. &,$+ 11 \mathrm{~h}$ & 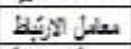 & \multirow{2}{*}{ 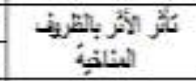 } \\
\hline.,+ &.,$r$ & $\cdot, \mathrm{i}$ &.,$t$ &.,+ &,$+ \pi$ & 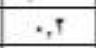 &.,+7 &,+ 2 & (1) & \\
\hline$*,+, \pi 1$ & $* *, \cdots$ & $\theta,+v$ & $* *_{+, t i t}$ & $*_{*, t, 1 \%}$ & $* *, t \leq t$ & $2,1, A$ &., $1 y^{4}-$ &., $184-$ & مبلد الهيكا & \multirow{2}{*}{ حالة لبية بصدة علدة - } \\
\hline$\because, \cdots \psi$ &,$\ldots$ &., 1 & $\ldots \ldots$ & $\cdot, \cdots$ &,$\ldots$ & $\cdot, 1$ &,$++h$ &., 4 & 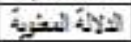 & \\
\hline ., & $* *_{r, 0}$ ro & $\therefore, * A V$ & $*, \mathrm{nut}$ &,+ 167 & $*, \mathrm{r} \mathrm{r}_{\text {. }}$ &,+ 14 & $8,100-$ & $\because+, \mathrm{TA},-$ & 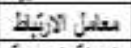 & \multirow{2}{*}{ حلأ سكان لاجسَابية } \\
\hline,$+ T$ & $\sim \cdots$ & 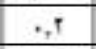 & $\cdots, \cdots A$ &,+ 1 & $\ldots, \ldots \gamma$ &,+ .4 &., $1 \pi$ & $*, \cdots 2$ & $4 y^{2}$ & \\
\hline., $1+4-$ & $\theta t a y$ & $\theta, T+\gamma$ & .110 &., 15. &., $1 \mathrm{v}$. &., .05 &., $1 \mathrm{~A}$. &.,$T V Y$ & سفل لازيكلة & \multirow{2}{*}{ مالة الهكل فئية } \\
\hline$\cdot, 4$ & 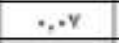 & 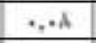 &,++ &.$\%$ &,$+ \pi$ & 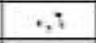 &,$+ v$ &,$+ \cdot \Lambda$ & (4) & \\
\hline$\cdot, 170$ & 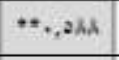 & $\cdot+\pi V$ & $*_{*, i * i}$ & $\cdots,+4 \lambda$ & 8 & - & $\theta,,+1,4$ & $\theta, \mathrm{ttt} t$ & معنل الئبكا & \multirow{2}{*}{ 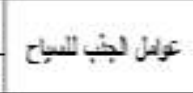 } \\
\hline$\cdot, 1$ & $+\cdots$ &,$+ y$ & $\ldots, \cdots$ & $\because \cdots$ & $\ldots \ldots$ &.$\cdots$ & $\ldots+,+y$ &,+-1 & 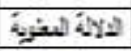 & \\
\hline., $1 A 4$ &., 17. & 8,173 &., $1 \pi$ &.,+27 &., 170 & $\therefore,+4 i$ &., 11 &,$++V Y$ & 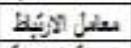 & \multirow{2}{*}{ 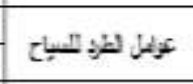 } \\
\hline.,+ &.,+ &.,$T$ &.,$\pi$ &,+ 1 &,$+ \pi$ &.,$i$ &.,+ &,, 2 & $4 x^{2}$ & \\
\hline$\tau \cdot \vartheta$ & $*+, y 21$ & $\cdot \cdot * \lambda$ & $*_{\bullet, \pm 49}$ & & & & $\bar{*}, \mathrm{rq}_{4}$ & & سبلد المينبة & \multirow{2}{*}{ كائة (لمكن بأسباح } \\
\hline,$+ \cdot t$ &,$+ \ldots$ & $\cdot, 7$ & $\because \ldots$ &,,$\cdots 1$ & $\therefore \ldots$ & $\ldots, \ldots$ & $\ldots, \ldots$ & $\ldots, \ldots$ & 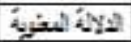 & \\
\hline., 174 & $4,17$. &., 145 &., 11. & , 194 &., $1 \mathrm{YY}$ & $\cdot,+4$ & $4,1,4$ &., $15 \gamma$ & بوليل الوزئكا & إبلدي الهئبل \\
\hline$+\%$ &.,$\%$ & 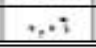 & $+t^{*}$ &,++ &,++ &.,$\hat{A}$ &,$++\psi$ &,$+ T$ & (4) & \\
\hline
\end{tabular}


من الجدول السابق يوضح قيمة الارتباط بين أبعاد الانتبيان ومقياس تقدير الثخصية لعينة

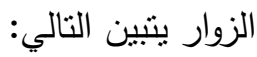

ه توجد علاقة ارتباطية ذات دلاله إحصائية عند مستوى معنوية (0., •) بين إدراك قيمة

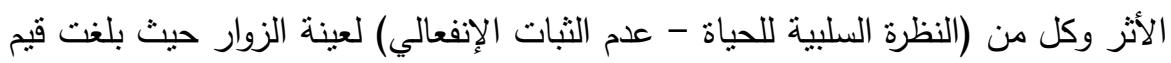

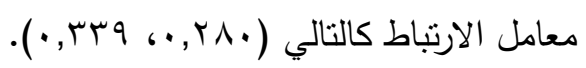
ه توجد علاقة ارتباطية عكسية ذات دلاله احصائية عند مستوى معنوية (0.,.) بين استخدام الأثز في نشاط اقتصادي أو تجاري أو صناعي وكل من (عدم التجاوب مع دأل الته الآخرين - الثقدير السلبي للذات - إجمالي مقياس تقدير الثخصية) لعينة الزوار حيث

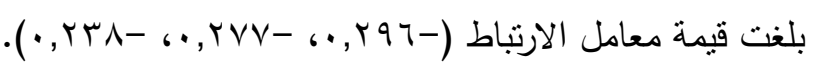

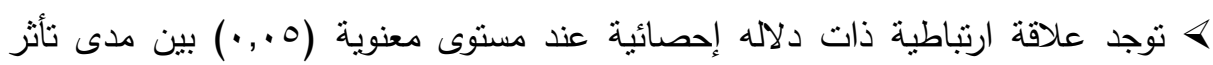

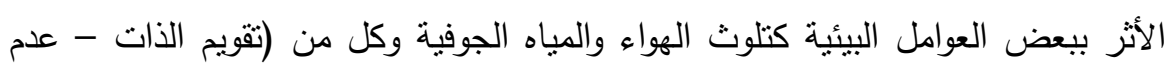
الكفاءة الثخصبة - التقدير السلبي للذات - العدوان/العداء - إجمالي مقياس تقدير

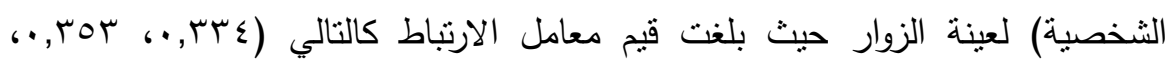

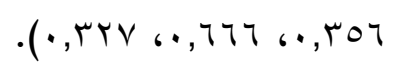

ه نوجد علاقة ارتباطية ذات دلاله إحصائية عند مستوى معنوية (0., •) بين حالة البيئة بصفة عامة وكل من (تقويم الذات - عدم الكفاءة الثخصية - التقدير السلبي للذات العدوان/العداء- إجمالي مقياس تقدير الثخصية) لعينة الزوار حيث بلغت قيم معاءة معامل

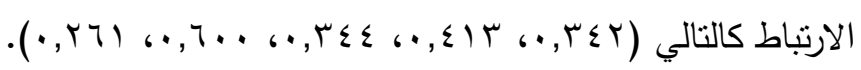

ه توجد علاقة ارتباطية ذات دلاله إحصائية عند مستوى معنوية (0. . •) بين حالة السكان الاجتماعية والاقتصادية وكل من (النظرة السلبية للحياة - تقويم الذات - التقدير السلبي

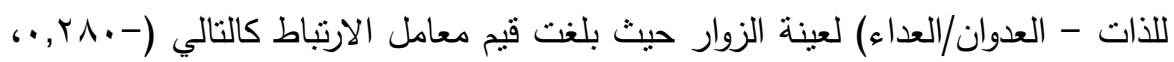

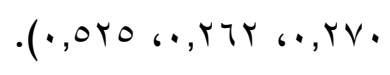

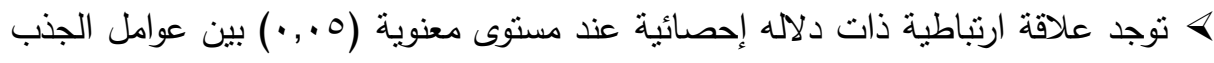

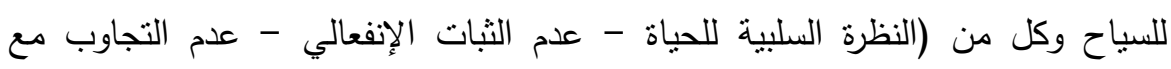


الآخرين - تقويم الذات - عدم الكفاءة الثخصية - التقدير السلبي للذات -

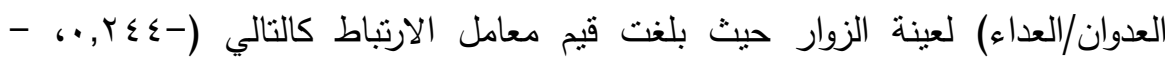

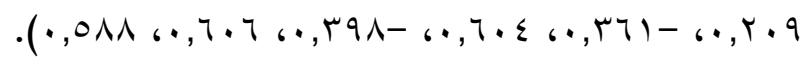

ه نوجد علاقة ارتباطية ذات دلاله إحصائية عند مستوى معنوية (0 ., •) بين علاقة السكان بالسياح وكل من (النظرة السلبية للحياة - عدم الثبات الإنفعالي - عدم التجاوب مع دعاله الآخرين - تقويم الذات - عدم الكفاءة الثخصية - التقدير السلبي للذات العدوان/العداء- إجمالي مقياس تقدير الثخصية) لعينة الزوار حيث بلغت قيم معامل

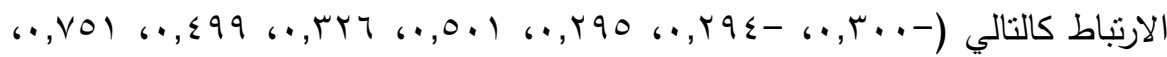

$$
\cdot(\cdot, r \cdot V
$$

ه بينما لا توجد علاقة ارتباطية ذات دلاله إحصائية عند مستوى معنوية (0. . •) بين باقي أبعاد الاستبيان ومقياس تقدير الثخصية. وهو ما أكدته دراسة عنان محمد على بعنوان "ملامح تغير علاقات العات الحياة اليومية: دراسة

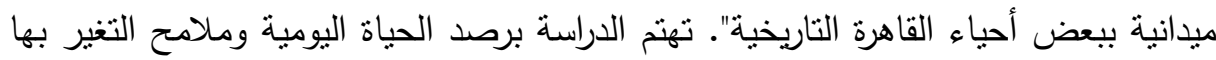
من خلال منومة العلاقات التى تتم عبر عدة مستويات، هى المجتمع المحلى، الحارة، الجيزة،

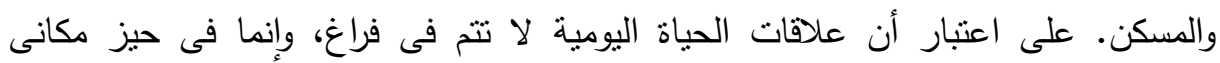

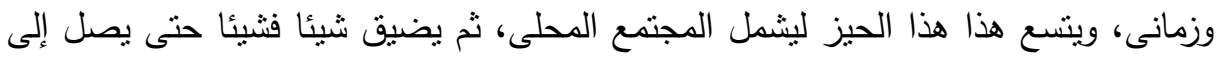
داخل الوحدة السكنية. كما أنشارت دراسة Nsizwazikhona Simon Chili والتى جاءت تحت عنوان : تصورات وتوجهات أعضاء المجتمع المحلى تجاه نأثثرات السياحة والتتمية المستدامة: دراسة

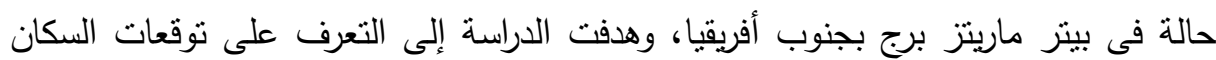
المحليين تجاه السياحة ودورها فى تحقيق التتمية المستدامة، واعتمدت الدراسة على نظرية التغير الأجتماعي كتوجه نظري، وتوصلت الدراسة إلى مجموعة من النتائج ومنها :

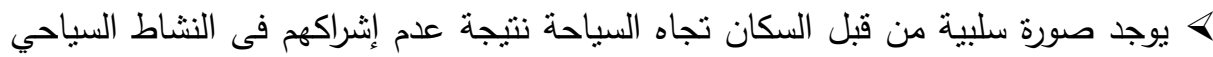
وإقتصار الأمر على المتعلمين ومن يجيدون اللغات الاجنبية . 
ه يوجد تقبل لتحسين صورة الذهنية عن أهمية السياحة ودورها فى تحقيق التتمية المستدامة

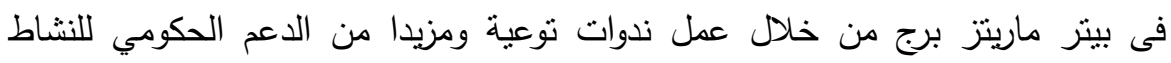

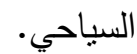

ه يعد تقبل الأخر والتسامح من أهم القيم التقافية التى تسهم فى دعم النشاط السياحي والتفاعل مع السياح فى منطقة بيتز ماريتز برج بجنوب أفريقيا.

\section{توكياتش الصورامة}

ه توصي الدراسة بأنه يجب الأهنمام بالبعد الأجتماعي الذي لم يأخذ حقه من الدراسات

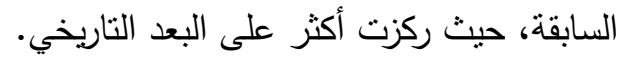

ه ترى الدراسة أنه من الضروري التركيز على ديناميات التفاعل التي تتجم عن العلاقة بين السكان المقيمين في تلك المناطق الأثرية والمناطق المحيطة بها حيث أن أغلب الدراسات أهتمت أكثر بإعادة إحياء الحيز الأثري والمنطقة الأثرية. ك توصي الدراسة أيضا بعدم إغفال دور العنصر البشري في إحداث عملية النتمية السياحية،كذلك وضع خطط تتموية للمناطق الأثرية دون الأخذ في الأعنبار مواقف وتصورات السكان المحليين المقيمين في تلك المناطق، \& تفعيل الدور الثقافي والسياحي في نشر الوعي بين السكان بأهمية الأثر والحفاظ عليه. ه تضافر الجهود بين الجهات الحكومية المختلفة (وزارات هيئات محافظات) للأهنمام بالمناطق الأثرية وتلبية إحتاجاتها.

\section{zall}

أحمد الجلاد: قضايا ومشكلات التتمية البيئية بالمناطق الأثرية السياحية :دراسة ميدانية بمدينة

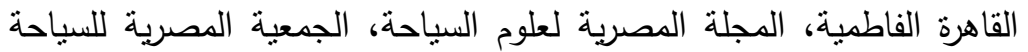

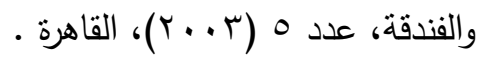


أحمد ماهر ابراهيم عدوي. تقييم مفاهيم السياحة البيئية لدى فئات مختلفة من المجتمع، رسالة

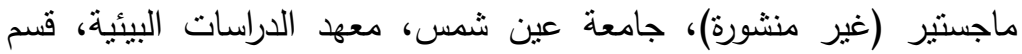

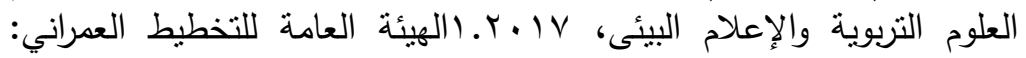

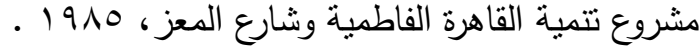

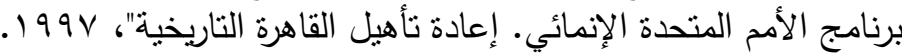

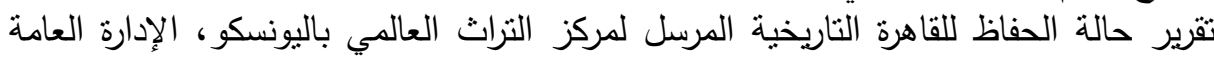

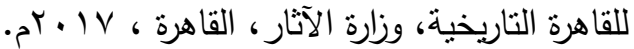

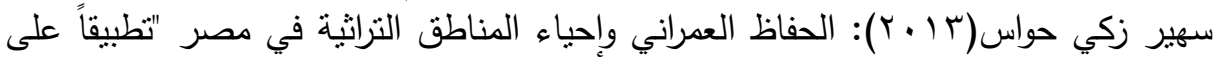

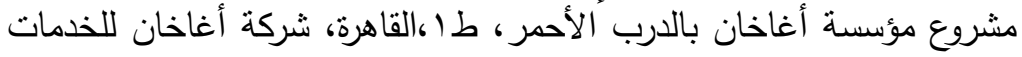
الثقافية.

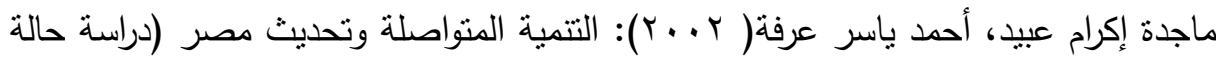

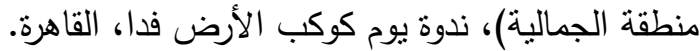

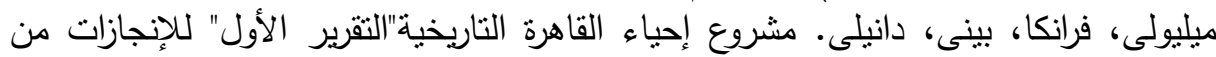

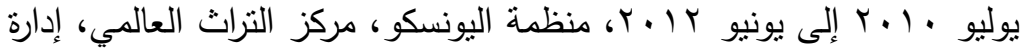

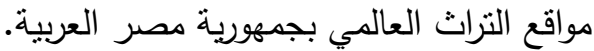

Andrew Lepp (2007). Case Study Residents' Attitudes Towards Tourism In Bigodi, Tourism Management 28 : 876-885

Wakiuru Wamwara-Mbugual and T. Bettina Cornwell( 2008), The Impact of Tourism on The Consumption Environment: Coping and Potential Praxis In Malindi, Kenya,African Journal of Business Management Vol.2 (6), Pp. 099-110. 
أحمد مصطفى العتيق وآخرون

\title{
THE DYNAMICS OF INTERACTION BETWEEN \\ URBAN MAN AND ARCHEOLOGICAL SPACE IN \\ CAIRO - A FIELD STUDY FOR SOCIO-BEHAVIOR \\ AND ATTRACTION AND EXPULSION FOR \\ TOURISTS
}

\author{
Al-Atiq, A. M. ${ }^{(1)}$; Ebeid, Magda, I. $^{(1)}$; Abd El-Latif, M. A. ${ }^{(2)}$ \\ and Ahmed, Aida, A. H. \\ 1) Institute of Environmental Studies \& Research, Ain Shams \\ University 2) Faculty of Tourism \& Hotels, Al-Mansoura University
}

\begin{abstract}
Historical Cairo is enriched with important archeological and historical places that embody the richness of the city. Cairo city has been included in the world heritage list in 1979 under the title "Islamic Cairo", for its remarkable archeological, historical, and civilizational importance. This study purpose is to identify the personal aspects in a selected sample from inhabitants, employees, visitors, and tourists through applying scale of personal evaluation, and for identifying also the human being's relationship to the archeological environment (affect and effect). The study also drives at examining the relationship between inhabitants, visitors, and personnel in tourism field and the monumental materialistic environment; examining as well the relationship between tourists and the materialistic archeological background, identifying as well the personal characteristics, either the positive or the negative within the monumental environment. The study follows the descriptive method through a qualitative quantative depiction. The study uses the inductive analysis in order to analyze, explain, and deduce results.

The study population is selected from residents in historical Cairo and employees who are working in archeological areas, in addition to visitors and tourists. Questionnaire forms consistent of (190) items are

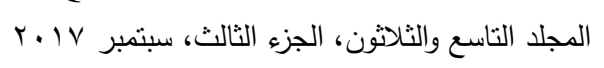


distributed as follows: (117 forms for residents, 43 forms for visitors and tourists, 30 forms for employees and workers in tourism). The study comes to these results: There are significant statistical differences at (0.05) significance level between average scores of (employees and visitors) and (employees and residents) on the full Scale of Evaluating Personality; while there are no significant statistical differences at (0.05) significance level between average scores of (residents and visitors). There are significant statistical differences at (0.05) significance level between average scores of (employees and inhabitants) and dimensions of Scale of Evaluating Personality. There are no significant statistical differences at (0.05) significance level between average scores of (employees and inhabitants) regarding the dimensions of Scale of Evaluating Personality. There are significant statistical differences at (0.05) significance level between average scores of the full questionnaire and dimensions of Scale of Evaluating Personality. The study recommends the need for considering the social dimension, focusing only on the historical only and dynamics of interaction of the relationship between residents and the surrounding areas. The study also recommends not neglecting the role of the human element in producing tourist development process, setting developmental plans for archeological areas with no regards to local residents' perceptions. 